\title{
An interacting segment model of molecular electric tensor properties: Application to dipole moments, polarizabilities, and hyperpolarizabilities for the halogenated methanes ${ }^{a)}$
}

\author{
C. K. Miller \\ Sandia National Laboratories, Division 4214, Albuquerque, New Mexico 87185 \\ B. J. Orr ${ }^{\mathrm{b})}$ and J. F. Ward \\ Randall Laboratory of Physics, The University of Michigan, Ann Arbor, Michigan 48109 \\ (Received 3 December 1980; accepted 8 January 1981)

\begin{abstract}
A previously developed interacting segment model [ISM - see J. Chem. Phys. 67, 2109 (1977)] is applied to a full-scale treatment of the electric dipole moments, isotropic and anisotropic polarizabilities, and hyperpolarizabilities of a series of 12 halogenated methane molecules $\mathrm{CX}_{n} \mathrm{Y}_{4-n}(\mathrm{X}, \mathrm{Y}=\mathrm{H}, \mathrm{F}, \mathrm{Cl} ; n=0-4)$. The ISM scheme enables the molecular properties considered to be fitted in terms of a set of "bare" electric tensor parameters for each bond, which are modified ("dressed") by intramolecular electrostatic interactions. The computed results of the ISM scheme, and of a corresponding interaction-free bond additivity model, are discussed in relation to the following: choice of geometric and bond parameters, quality of fit to experimentally determined molecular and bond properties, and predictive potential and general physical validity of the model. It is concluded that the ISM approach represents a substantial improvement over simple bond additivity as a basis for understanding molecular electric tensor properties.
\end{abstract}

\section{INTRODUCTION}

The interaction of a molecule with a uniform electric field $\mathbf{E}$ can for many purposes be described in terms of a variety of electric tensor properties: the permanent electric dipole moment $\mu$, the polarizability tensor $\alpha$, and hyperpolarizability tensors $\beta, \gamma, \ldots$ These properties appear as coefficients in an expansion in powers of $E$ of the total electric dipole moment $\mu(E)$ of the molecule in that field. For conceptual purposes, it is simplest to regard $E$ as time independent, in which case the coefficients are static in nature. However, experimental studies generally require that $\mathbf{E}$ be time dependent so that different contributions can be separated by Fourier analysis of $\mu(\mathbf{E})$; a variety of dynamic coefficients $\alpha, \beta, \gamma, \ldots$, dependent on field frequencies $\omega$, then emerge.

The task of correlating experimental observables containing tensor elements of $\mu, \alpha, \beta$, and $\gamma$ for series of structurally related molecules has traditionally been based on models in which a molecule is viewed as a structure of segments or bonds, each characterized by a set of transferable electric tensor parameters. Such models serve to impose physically realistic constraints on the correlation of molecular observables, in the absence of $a b$ initio calculations of adequate accuracy.

One such correlation scheme for molecular electric tensor properties is based on an interacting segment model (ISM), in which allowance is made for electrostatic interactions between adjacent segments of the molecule. This has been described in a previous publication ${ }^{1}$ (hereafter referred to as I). In the ISM for a

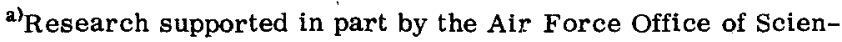
tific Research under Grants Nos. $72-2302$ and 77-3225, by the U. S. / Australia Cooperative Science Program, and by the Department of Energy.

${ }^{b)}$ Permanent address: School of Chemistry, University of New South Wales, Kensington, N. S. W. , Australia 2033.
}

given molecular electric tensor property $\chi$, it is supposed that the $i$ th segment of the molecule can be assigned a "bare" tensor $\chi_{i}$ localized at a point (termed the "active center") in that segment. Dipolar electrostatic interactions with other segments in the molecule then modify $\chi_{i}$, to yield a "dressed" tensor $\hat{\chi}_{i}$ which can be used to construct the overall molecular tensor $\chi$ by summing the $\hat{\chi}_{i}$ tensors for all segments $i$. The concepts associated with this model and its relationship to other correlation schemes, including the bond additivity approximation (BAA) in which interactions between segments are assumed negligible, have been discussed at length in $\mathrm{I}$. The results of preliminary computations, to correlate electric dipole moment ${ }^{1}$ and hyperpolarizability $^{2}$ data for a series of halogenated derivatives of methane, have also been reported. The present paper aims to extend these preliminary studies to a full-scale correlation of a wide variety of molecular electric tensor observables for the same series of molecules.

\section{MOLECULAR OBSERVABLES}

Molecular observables which involve elements of the electric tensor properties $\mu, \alpha, \beta$, and $\gamma$ are available from a wide variety of experiments. ${ }^{3}$ Some of the linear combinations of tensor components which appear as observables have been defined in Table VI of I. " Those which are used in the treatment which follows are identified and further summarized below:

$\mu \quad$ The permanent molecular electric dipole moment, taken to lie along (and to define) the molecular $Z$ axis.

$\alpha^{0} \quad$ The isotropic (scalar) part of the static (dc) polarizability tensor.

$\alpha^{\omega} \quad$ The isotropic part of the optical polarizability tensor.

$\left(\alpha_{z Z}^{\omega}-\alpha^{\omega}\right)$ An optical polarizability anisotropy which contributes directly to the Kerr effect 
(electric birefringence) of a dipolar molecule.

The depolarization ratio for molecular

Rayleigh scattering, which can in turn be expressed in terms of a dimensionless anisotropy parameter $\kappa^{2}$ as $\rho=3 \kappa^{2} /\left(5+4 \kappa^{2}\right)$, assuming that the incident light is linearly polarized. ${ }^{3}$

$\beta^{\text {SHG }} \quad$ A vectorlike hyperpolarizability observable which contributes to molecular dc electric field-induced second harmonic generation (ESHG).

$\beta^{\mathrm{K}} \quad$ The corresponding hyperpolarizability observable which contributes to the Kerr effect.

$\gamma^{\text {ESHG }} \quad$ A scalar hyperpolarizability observable which contributes to molecular ESHG.

$\gamma^{\mathrm{K}} \quad$ The corresponding hyperpolarizability observable from the Kerr effect.

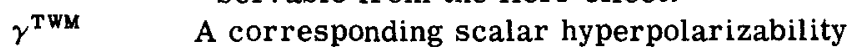
observable which determines coherent three-wave mixing (TWM) for molecules. ${ }^{3}$

$\gamma^{\text {THG }} \quad$ The corresponding hyperpolarizability observable from third harmonic generation (THG).

Several explanatory comments are appropriate. For the optical polarizability tensor $\alpha^{\omega}$, the three parameters $\alpha^{\omega},\left(\alpha_{z z}^{\omega}-\alpha^{\omega}\right)$, and $\rho$ are not necessarily independent, nor are they the only optical polarizability observables which may be available for a given molecule. For example, any molecule which has three- or higherfold rotational symmetry (e.g., $C_{3 v}$ molecules such as $\mathrm{CH}_{3} \mathrm{X}$ and $\mathrm{CHX}_{3}$ ) must conform to the following relationship:

$$
\begin{aligned}
& \left(\alpha_{Z Z}^{\omega}-\alpha^{\omega}\right)=\frac{2}{3}\left(\alpha_{11}^{\omega}-\alpha_{1}^{\omega}\right), \\
& 5 \rho /(3 \rho-4)=\left[\left(\alpha_{Z Z}^{\omega}-\alpha^{\omega}\right) / 2 \alpha^{\omega}\right]^{2}=\left[\left(\alpha_{11}^{\omega}-\alpha_{\perp}^{\omega}\right) / 3 \alpha^{\omega}\right]^{2},
\end{aligned}
$$

where subscripts $\|$ and $\perp$ denote components parallel and perpendicular to the molecular $(Z)$ axis, respectively. Equations (1) and (2) serve to limit the number of independent polarizability observables for a molecule with such symmetry to two [for example, $\alpha^{\omega}$ and $\left.\left(\alpha_{z Z}^{\omega}-\alpha^{\omega}\right)\right]$. However, for molecules with lower symmetry (e.g., $\mathrm{C}_{2 v}$ molecules such as $\mathrm{CH}_{2} \mathrm{X}_{2}$ ) these restrictions are not present, so that three independent polarizability observables [for example $\alpha^{\omega},\left(\alpha_{Z Z}^{\omega}-\alpha^{\omega}\right)$, and $\rho$ ] may be specified. Moreover, in favorable cases $^{5,6}$ additional information about the anisotropy of $\alpha^{\omega}$ may be obtained in the form of a value of $\left(\alpha_{X X}^{\omega}-\alpha_{Y Y}^{\omega}\right)$ from the distribution of intensity in the rotational $\mathrm{Ra}-$ man spectrum. Such information has recently become available for the molecule $\mathrm{CH}_{2} \mathrm{~F}_{2} \cdot{ }^{7}$

It may be noted that there are two experimentally derivable $\beta$-type observables $\left(\beta^{\text {SHG }}\right.$ and $\left.\beta^{\mathrm{K}}\right)$, both of which transform as vectors, and four scalar $\gamma$-type observables. As has previously been explained in I, the relative crudity of the approximations inherent in the ISM correlation scheme do not enable the subtleties of dispersion effects, which cause these $\beta$ - and $\gamma$-type observables to differ, to be considered in our analysis. Therefore, despite the substantial differences which can occur (for example, between $\beta^{\mathrm{SHG}}$ and $\beta^{\mathrm{K}}$ or between $\gamma^{\text {ESHG }}$ and $\gamma^{\mathrm{K}}$ ) we shall choose to extract a single preferred value of $\beta$ and of $\gamma$ from the data available, on the assumption that dispersion effects are negligible. Similarly, there are two types of isotropic polarizability $\alpha^{0}$ and $\alpha^{\omega}$; in view of the fact that experimental information about polarizability anisotropies refers most directly to the optical polarizability tensor $\alpha^{\omega}$, we shall choose to use preferred values of $\alpha^{\omega}$ rather than of $\alpha^{0}$ in our analysis.

Tables I and II present a compilation of molecular observables for use in the analysis which follows. A number of features of these tables should be emphasized. With regard to Table $I$, it is remarkable that a number of isotropic polarizabilities have never been accurately measured, particularly for $\mathrm{CH}_{2} \mathrm{~F}_{2}$ where neither $\alpha^{0}$ nor $\alpha^{\omega}$ is available from experiment. The wide range of values of $\rho$ from Rayleigh depolarization studies of the fluoromethanes should also be noted; this arises from spurious vibrational Raman contributions to $\rho$ in some experiments. Such vibrational Raman interferences were first noted by Bridge and Buckingham ${ }^{8}$ and have since been well characterized, ${ }^{9,6,12,13,7}$ to the extent that the results of Ref. 7 are believed to be free of such interferences and yield acceptable agreement with values of $\left(\alpha_{z z}^{\omega}-\alpha^{\omega}\right)$ from the Kerr effect for $\mathrm{CH}_{3} \mathrm{~F}$ and $\mathrm{CHF}_{3} .{ }^{14}$ It is also noteworthy that, even in the instances where Kerr effect results yield a magnitude of $\left(\alpha_{z Z}^{\omega}-\alpha^{\omega}\right)$ for $C_{3 v}$ molecules inferior in accuracy to that from $\rho$, the Kerr effect results are still useful in determining the sign of $\left(\alpha_{z Z}^{\omega}-\alpha^{\omega}\right)$. Attention should be drawn to the determination ${ }^{7}$ of $\left(\alpha_{X X}^{\omega}-\alpha_{Y Y}^{\omega}\right)$ for $\mathrm{CH}_{2} \mathrm{~F}_{2}$ (see footnote $\mathrm{y}$ of Table I). With regard to Table II, it should be remarked that preferred values of $\beta$ and $\gamma$ for the halogenated methanes have without exception been based on results from ESHG experiments, ${ }^{2,15}$ in view of the acknowledged ${ }^{10}$ superiority of that technique.

In addition to electric tensor observables for a molecule as a whole, it is possible to obtain estimates of properties for individual segments or bonds. The sources of such data are threefold: $a b$ initio theory, adapted to identify individual bond contributions, experimental results, based on symmetry-determined relationships between a molecular property and its bond contributions, and spectroscopic intensity data for infrared- or Raman-active molecular bending modes, with the assumption that a bond model provides an adequate description. Relevant data of these types are summarized in Table III. Although the data are not in general direct observables, they are believed to be of sufficient reliability to provide useful constraints on values of dressed bond properties in the present context. One issue which merits special comment relates to the determination of $\hat{\mu}(\mathrm{C}-\mathrm{H})$. In addition to the values given in Table III, there exist a diversity of $a b$ initio theoretical results ${ }^{17}$ which range in magnitude up to $\sim 2 \mathrm{D}$ and which are evenly divided as to the sense of polarization $\left(\mathrm{C}^{-}-\mathrm{H}^{+}\right.$or $\left.\mathrm{C}^{+}-\mathrm{H}^{-}\right)$. The positive $\operatorname{sign}^{16}$ of the octopole moment of $\mathrm{CH}_{4}$ causes us to favor the former sense and to adopt the value: $\hat{\mu}(\mathrm{C}-\mathrm{H})=+0.30 \pm 0.06 \mathrm{D}$.

Finally, it is relevant to comment on the sense of the 
TABLE I. Observed and preferred polarizability data for the halogenated methanes. ${ }^{a}$

\begin{tabular}{|c|c|c|c|c|c|c|c|c|}
\hline \multirow[b]{2}{*}{ Molecule } & \multicolumn{2}{|c|}{$\alpha^{0}$} & \multicolumn{2}{|c|}{$\alpha^{\omega}$} & \multicolumn{2}{|c|}{$10^{3} \rho$} & \multicolumn{2}{|c|}{$\left(\alpha_{Z z}^{\omega}-\alpha^{\omega}\right)$} \\
\hline & Obs. & Pref. & Obs. ${ }^{c}$ & Pref. & Obs. $^{d}$ & Pref. & Obs. $^{e}$ & Pref. \\
\hline $\mathrm{CCl}_{4}$ & 11.2 & $11.2(2)$ & $\begin{array}{l}10.47^{8} \\
10.55^{8}\end{array}$ & $10.5(1)$ & $\cdots$ & $\cdots$ & $\ldots$ & $\cdots$ \\
\hline $\mathrm{CHCl}_{3}$ & $\begin{array}{c}10.5 \\
10.0 \\
9.5^{\mathrm{h}}\end{array}$ & $9.5(5)$ & $\begin{array}{l}8.50^{f} \\
8.52^{B}\end{array}$ & $8.5(1)$ & $\begin{array}{l}6.52(5) \\
6.52(5)^{\mathrm{i}} \\
6.4^{1}\end{array}$ & $6.5(3)^{\mathrm{m}}$ & $\begin{array}{l}-2.0(4)^{j} \\
\pm 1.78(6)^{k}\end{array}$ & $-2.0(4)$ \\
\hline $\mathrm{CH}_{2} \mathrm{Cl}_{2}$ & 7.9 & $7.9(5)$ & $\begin{array}{l}6.80^{\mathbb{P}} \\
6.53^{\mathbb{B}}\end{array}$ & $6.6(2)$ & $\begin{array}{l}11.24(4) \\
10.81(3)^{\mathrm{n}}\end{array}$ & $11.0(3)^{\mathrm{m}}$ & $-0.61(7)^{\circ}$ & $-0.61(7)$ \\
\hline $\mathrm{CH}_{3} \mathrm{Cl}$ & $\begin{array}{l}5.4 \\
5.5 \\
4.72^{p}\end{array}$ & 4. $7(1)$ & $\begin{array}{l}4.53^{t} \\
4.58^{\mathrm{g}} \\
4.56^{\mathrm{a}}\end{array}$ & $4.55(5)$ & $\begin{array}{l}7.66(4) \\
7.55(9)^{\mathrm{n}} \\
7.6(1)^{\mathrm{i}} \\
7.5(2)^{1}\end{array}$ & $7.6(3)^{\mathrm{m}}$ & $\begin{array}{l}+1.3(2)^{\mathrm{J}} \\
\pm 1.03(5)^{k}\end{array}$ & $+1.3(2)$ \\
\hline $\mathrm{CH}_{4}$ & $\begin{array}{l}2.59 \\
2.62 \\
2.593^{r}\end{array}$ & $2.59(1)$ & $\begin{array}{l}2.61^{\mathrm{s}} \\
2.62^{\mathrm{t}} \\
2.59^{\mathrm{u}}\end{array}$ & $2.60(2)$ & $\cdots$ & $\cdots$ & $\cdots$ & $\cdots$ \\
\hline $\mathrm{CH}_{3} \mathrm{~F}$ & $\begin{array}{l}3.6 \\
2.97^{\mathrm{p}}\end{array}$ & $3.0(1)$ & $\begin{array}{l}2.61^{p} \\
2.63^{\mathrm{a}}\end{array}$ & $2.61(3)$ & $\begin{array}{l}0.94(2)^{\mathrm{n}} \\
1.0(1)^{1} \\
0.83(5)^{1} \\
0.52(2)^{\mathrm{v}}\end{array}$ & $0.52(3)$ & $\begin{array}{l}+0.135(20)^{\mathrm{w}} \\
\pm 0.15(1)^{\mathrm{k}}\end{array}$ & $+0.135(20)$ \\
\hline $\mathrm{CH}_{2} \mathrm{~F}_{2}$ & $\cdots$ & {$[3.2(1)]^{x}$} & $\cdots$ & {$[2.73(5)]^{x}$} & $\begin{array}{l}1.79(5) \\
0.95(3)^{\mathrm{n}} \\
0.57(3)^{\mathrm{v}}\end{array}$ & $0.57(5)$ & $\begin{array}{l}-0.014(6)^{\mathrm{w}} \\
\pm 0.03(15)^{\mathrm{y}}\end{array}$ & $-0.014(6)$ \\
\hline $\mathrm{CHF}_{3}$ & $\begin{array}{l}3.3^{\mathrm{h}} \\
3.57^{\mathfrak{p}}\end{array}$ & $3.6(1)$ & $2.80^{2}$ & $2.80(3)$ & $\begin{array}{l}0.50(5) \\
0.50(4)^{\mathrm{n}} \\
0.54(5)^{1} \\
0.245(12)^{\vee}\end{array}$ & $0.25(2)$ & $\begin{array}{l}-0.145(30)^{\mathrm{w}} \\
\pm 0.115(10)^{\mathrm{k}}\end{array}$ & $-0.145(30)$ \\
\hline $\mathrm{CF}_{4}$ & $\begin{array}{l}4.02 \\
3.86^{\text {aa }} \\
3.838^{r}\end{array}$ & $3.84(1)$ & $\begin{array}{l}2.85^{z} \\
2.92^{\mathrm{g}} \\
2.86^{\mathrm{a}}\end{array}$ & $2.85(2)$ & $\cdots$ & $\cdots$ & $\cdots$ & $\cdots$ \\
\hline $\mathrm{CF}_{3} \mathrm{Cl}$ & 5. $59^{g}$ & $5.6(1)$ & $\cdots$ & {$[4.8(1)]^{x}$} & $4.2(1)^{1}$ & 4. $2(3)^{\mathrm{m}}$ & $\pm 0.805(75)^{k}$ & $\cdots$ \\
\hline $\mathrm{CF}_{2} \mathrm{Cl}_{2}$ & 8.0 & $8.0(5)$ & $\cdots$ & {$[6.7(2)]^{x}$} & $6.87(5)^{\mathfrak{n}}$ & $6.9(3)^{\mathfrak{n}}$ & $-0.17^{\mathrm{ab}}$ & $-0.17(10)$ \\
\hline $\mathrm{CFCl}_{3}$ & 9.4 & $9.4(5)$ & $\cdots$ & {$[8.6(2)]^{x}$} & $\cdots$ & $\cdots$ & $-0.51^{a b}$ & $-0.51(20)$ \\
\hline
\end{tabular}

${ }^{2}$ All polarizabilities are in $\AA^{3}\left(10^{-24} \mathrm{~cm}^{3}\right)$ and refer to an optical wavelength $\lambda=6328 \AA$ unless otherwise specified. The parameter $\rho$ is dimensionless. Uncertainty estimates are indicated in parentheses. Preferred values are based on a critical appraisal of the quality of the data for the purposes of the present analysis.

Isotropic static polarizabilities determined from dielectric constants of gases. Data are obtained from the compilations of Landolt-Börnstein [Zahlenwerte und Funktionen (Springer, Berlin, 1951), Vol. I, Sec. 3, pp. 514, 515], unless otherwise specified.

'Isotropic optical polarizabilities from refractive indices of gases.

d $\rho$ is the depolarization ratio for Rayleigh scattered light, as determined by Bridge and Buckingham ${ }^{8}$ unless otherwise specified.

${ }^{e}$ Values of $\left(\alpha_{Z Z}^{\omega}-\alpha^{\omega}\right)$ can be obtained directly from Kerr effect data for dipolar molecules and, in the case of $C_{3 v}$ molecules, should be related to $\rho$ by Eqs. (1) and (2).

${ }^{1}$ K. L. Ramaswamy, Proc. Indian Acad. Sci. Sect. A 4, 675 (1936).

${ }^{{ }^{3}}$ H. Lowery, Proc. Phys. Soc. (London) 38, 421 (1927); H. Lowery and T. S. Hartley, ibid. 43, 559 (1931); H. Lowery, Proc. R. Soc. London, Ser. A 133, 188 (1931).

${ }^{n}$ Calculated from the dielectric data of A. D. Buckingham and R. E. Raab, J. Chem. Soc. 1961, 5511; see also Ref. 3.

'G. R. Alms, A. K. Burnham, and W. H. Flygare, J. Chem. Phys. 63, 3321 (1975); see also Ref. 9. Measurements made with $\lambda=4880 \AA$.

${ }^{j}$ Obtained by analysis of Kerr effect data ${ }^{10}$ by the procedure of Buckingham and Orr. ${ }^{11}$

Obtained from the preferred value of $\rho$, using Eq. (2). The sign of $\left(\alpha_{z Z}^{\omega}-\alpha^{\omega}\right)$ is undetermined by this method.

'See Ref. 13.

${ }^{m} A$ relatively large uncertainty of $\pm 3 \times 10^{-4}$ has been placed on all values of $\rho$ which do not specifically exclude vibrational Raman interferences (see text).

"See Ref. 12 .

${ }^{\circ}$ See Ref. 10.

${ }^{D} \mathrm{H}$. Sutter and R. H. Cole, J. Chem. Phys. 52, $132(1970)$.

${ }^{9} A$. R. Blythe, J. D. Lambert, P. J. Petter, and H. Spoel, Proc. R. Soc. London, Ser. A 255, 427 (1960). Measurements made with $\lambda=5462 \AA$.

${ }^{n}$ T. K. Bose, J. S. Sochanski, and R. H. Cole, J. Chem. Phys. 57, 3592 (1972).

${ }^{3}$ H. E. Watson and K. L. Ramaswamy, Proc. R. Soc. London, Ser. A 156, 144 (1936).

${ }^{t}$ A. D. Buckingham and C. Graham, Proc. R. Soc. London, Ser. A 336, 275 (1974).

"J. M. St. -Arnaud and T. K. Bose, J. Chem. Phys, 65, 4854 (1976). 


\section{TABLE I (Continued)}

'See Refs. 6 and 7. These experiments exclude vibrational Raman contributions to the depolarization ratio $\rho$, which cause previous measurements ${ }^{8,9,12,13}$ of small values of $\rho$ to be erroneously high. Measurement made with $\lambda=5145 \AA$.

"Results based on a re-analysis ${ }^{13,7}$ of Kerr effect data. ${ }^{11}$

${ }^{x}$ Estimated, in the absence of experimental results, on the basis of the BAA. Condensed-phase values of $\alpha^{\omega}$ for $\mathrm{CF}_{3} \mathrm{Cl}_{1} \mathrm{CF}_{2} \mathrm{Cl}_{2}$, and $\mathrm{CFCl}_{3}$ have recently been measured [A. Yoshihara, A. Anderson, R. A. Aziz, and C. C. Lim, Chem. Phys. 51, 141 (1980)] as $4.43(3), 6.58(4)$, and $8.52(5) \AA^{3}$, respectively, with $\lambda=5145 \AA$.

'Determined from the intensity distribution of the rotational Raman spectrum. ${ }^{7}$ These measurements also yield an estimate of the the anisotropy $\left(\alpha_{\mathscr{X} X}^{\omega}-\alpha_{Y Y}^{\omega}\right)=+0.291(15) \AA^{3}$, by combining the rotational Raman intensity results with $\left(\alpha_{Z Z}^{\omega}-\alpha^{\omega}\right)$ from the Kerr effect. Measurements made with $\lambda=5145 \AA$. The $X$ axis for $\mathrm{CH}_{2} \mathrm{~F}_{2}$ lies in the $\mathrm{CF}_{2}$ plane.

¿K. L. Ramaswamy, Proc. Ind. Acad. Sci. Sect. A 2, 630 (1935).

${ }^{2 a}$ A. B. Tipton, A. P. Deam, and J. E. Boggs, J. Chem. Phys. 40, 1144 (1964).

abobtained by re-analysis of Kerr effect measurements at a single temperature [R. J. W. Le Fèvre and G, L. D. Ritchie, J. Chem. Soc. 3520 (1965)], assuming values of $\beta$ and $\gamma$ from ESHG studies.

$Z$ axis in our coordinate system for the dipolar halogenated methane molecules. The electric dipole moment $\mu$ (and with it, the molecular $Z$ axis) is directed along the major symmetry axis of the molecule and is taken to be in the sense $-\mathrm{F}_{n} \mathrm{CCl}_{4-n}^{+},{ }^{+} \mathrm{H}_{n} \mathrm{CF}_{4-n}^{-}$, or ${ }^{+} \mathrm{H}_{n} \mathrm{CCl}_{4-n}^{-}$. This choice of axis direction is consistent with the experimentally determined ${ }^{18}$ polarizations ${ }^{+} \mathrm{HCF}_{3}^{-}$and ${ }^{+} \mathrm{H}_{3} \mathrm{CCl}^{-}$, as well as with accepted electronegativity trends.

\section{THEORY AND COMPUTATIONAL PROCEDURE}

As proposed in I and outlined above, we consider each molecule as a well defined geometric arrangement of bonds. The electrical properties of an isolated bond are represented by a set of bare, point electric tensor properties which are taken to be concentrated at a specific location (the active center) in the bond. Bonds in a molecule interact electrostatically and their resulting

TABLE II. Electric dipole moments and hyperpolarizabilities for the halogenated methanes.

\begin{tabular}{|c|c|c|c|c|c|c|c|c|}
\hline Molecule & $\begin{array}{l}10^{18} \mu(\text { esu }) \\
\text { Preferred }^{\mathbf{2}}\end{array}$ & ESHG $^{\mathrm{h}}$ & $\begin{array}{l}10^{30} \beta(\mathrm{esu}) \\
\mathrm{Kerr}^{\mathrm{c}}\end{array}$ & Pref. ${ }^{1}$ & ESHG $^{b}$ & $\begin{array}{l}10^{36} \gamma(\mathrm{esu}) \\
\mathrm{Kerr}^{\mathrm{c}} \\
\end{array}$ & $\mathrm{TWM}^{\mathrm{d}}$ & Pref. $^{1}$ \\
\hline $\mathrm{CCl}_{4}$ & $\cdots$ & $\cdots$ & $\cdots$ & $\cdots$ & $\begin{array}{l}1.37(2)^{\bullet} \\
1.4^{p}\end{array}$ & $1.66(5)^{\mathrm{g}}$ & $1.4^{f}$ & $1.37(2)$ \\
\hline $\mathrm{CHCl}_{3}$ & $1.04(2)$ & $\begin{array}{l}+0.005(11)^{\circ} \\
+0.39^{1}\end{array}$ & $-0.7(5)^{8}$ & $+0.005(11)$ & 1. $12(3)^{\circ}$ & $\cdots$ & $0.98^{1}$ & $1.12(3)$ \\
\hline $\mathrm{CH}_{2} \mathrm{Cl}_{2}$ & $1.60(3)$ & $+0.017(10)^{\circ}$ & $+0.5(6)^{8}$ & $+0.017(10)$ & $0.92(3)^{e}$ & $\cdots$ & $\cdots$ & $0.92(3)$ \\
\hline $\mathrm{CH}_{3} \mathrm{Cl}$ & 1. $90(2)$ & $+0.057(6)^{\ominus}$ & $-0.1(5)^{8}$ & $+0.057(6)$ & $0.57(3)^{\circ}$ & $\cdots$ & $\cdots$ & $0.57(3)$ \\
\hline $\mathrm{CH}_{4}$ & $\cdots$ & $\cdots$ & $\ldots$ & .. & $\begin{array}{l}0.263(3)^{\mathrm{e}} \\
0.26^{\mathrm{f}}\end{array}$ & $0.24(1)^{\mathrm{h}}$ & $\begin{array}{l}0.28^{f} \\
0.19^{1}\end{array}$ & $0.263(3)$ \\
\hline $\mathrm{CH}_{3} \mathrm{~F}$ & $1.85(2)$ & $-0.244(18)^{\mathrm{j}}$ & $-0.26(20)^{x}$ & $-0.244(18)$ & $0.239(30)^{\mathrm{J}}$ & $\cdots$ & $\cdots$ & $0.239(30)$ \\
\hline $\mathrm{CH}_{2} \mathrm{~F}_{2}$ & $1.98(2)$ & $-0.180(8)^{j}$ & $-0.04(7)^{k}$ & $-0.180(8)$ & $0.154(11)^{\mathrm{j}}$ & $\cdots$ & $\cdots$ & $0.154(11)$ \\
\hline $\mathrm{CHF}_{3}$ & $1.65(2)$ & $\begin{array}{l}-0.108(4)^{\mathrm{J}} \\
-0.074^{\mathrm{f}}\end{array}$ & $+0.36(25)^{\mathrm{k}}$ & $-0.108(4)$ & $0.136(6)^{j}$ & $\ldots$ & $0,15^{\ell}$ & $0.136(6)$ \\
\hline $\mathrm{CF}_{4}$ & $\cdots$ & $\cdots$ & $\cdots$ & $\cdots$ & $0.091(3)^{\mathrm{J}}$ & $0.125(7)^{\mathrm{h}}$ & $\cdots$ & $0.091(3)$ \\
\hline $\mathrm{CF}_{3} \mathrm{Cl}$ & $0.50(1)$ & $-0.296(12)^{1}$ & $\cdots$ & $-0.296(12)$ & $0.306(13)^{1}$ & $\cdots$ & $\cdots$ & $0.306(13)$ \\
\hline $\mathrm{CF}_{2} \mathrm{Cl}_{2}$ & $0.51(5)$ & $-0.258(8)^{e}$ & $\cdots$ & $-0.258(8)$ & $0.61(1)^{\mathrm{e}}$ & $\cdots$ & $\cdots$ & $0.61(1)$ \\
\hline $\mathrm{CFCl}_{3}$ & $0.46(2)$ & $-0.132(41)^{e}$ & $\cdots$ & $-0.132(41)$ & $0.96(3)^{\mathrm{e}}$ & $\cdots$ & $\cdots$ & $0.96(3)$ \\
\hline
\end{tabular}

${ }^{2}$ Preferred values of electric dipole moment as adopted in Table III of I.

Values of $\beta^{\text {SHG }}$ and $\gamma^{\text {ESHG }}$ from ESHG experiments as defined in Table VI of I.

Values of $\beta^{\mathrm{K}}$ and $\gamma^{\mathrm{K}}$ from Kerr effect studies, as defined in Table VI of I.

${ }^{d}$ Values of $\gamma^{\mathrm{TWM}}=\left[2 \gamma_{\xi \xi \eta \eta}(-\omega-\Delta ; \omega, \omega,-\omega+\Delta)+\gamma_{\xi \eta \eta \xi}(-\omega-\Delta ; \omega, \omega,-\omega+\Delta)\right] / 15$ from coherent three-wave mixing (TWM) experiments. See also Ref. 3 .

'See Ref. 2.

${ }^{4} G$. Hauchecorne, F. Kerhervé, and G. Mayer, J. Phys. (Paris) 32, 47 (1971). Data normalized using the Kerr coefficient of argon.

See Ref. 10 .

${ }^{\mathrm{h}}$ See Ref. 11.

${ }^{1}$ W. G. Rado, Appl. Phys. Lett. 11, 123 (1967). Data normalized using the Kerr c refficient of argon.

'see Ref. 15.

${ }^{1}$ Results based on a re-analysis ${ }^{14,7}$ of Kerr effect data. ${ }^{11}$

${ }^{1}$ The uncertainties associated with our preferred values do not reflect the spread of values to be expected for $\beta$ and $\gamma$ observables derived from different experimental sources (for example, ESHG and Kerr effect) but are specific to the source (ESHG) from which preferred values have been derived. 
TABLE III. Electric tensor properties of individual bonds. ${ }^{a}$

\begin{tabular}{|c|c|c|c|c|}
\hline Bond & $\hat{\mu}(C-X)$ & $\hat{\alpha}(C-X)$ & $\Delta \hat{\alpha}(C-X)^{b}$ & $\hat{\gamma}(C-X)^{c}$ \\
\hline $\mathrm{C}-\mathrm{H}$ & $\begin{array}{r} \pm 0.33^{\mathrm{d}} \\
0.27^{\mathrm{e}}\end{array}$ & $\begin{array}{l}0.65^{1} \\
0.58^{8}\end{array}$ & $\begin{array}{l}0.31^{\mathrm{h}} \\
0.28^{\mathrm{l}} \\
0.39^{\mathrm{g}}\end{array}$ & 0.065 \\
\hline$C-F$ & $\ldots+$ & $0.71^{t}$ & $0.56^{\mathrm{h}}$ & 0.022 \\
\hline $\mathrm{C}-\mathrm{Cl}$ & $\ldots 1$ & $2.62^{l}$ & 1. $89^{\mathrm{h}}$ & 0.34 \\
\hline
\end{tabular}

aThe bond parameters $\hat{\mu}, \hat{\alpha}, \Delta \hat{\alpha}$, and $\hat{\gamma}$ are all taken to be

"dressed" quantities and to correspond to $C_{3 \nu}$ local symmetry, as is the case for a $\mathrm{C}-\mathrm{X}$ bond in a $\mathrm{CX}_{4}$ - type molecule. Units are, respectively: $D\left(10^{-18} \mathrm{esu}\right), \AA^{3}, \AA^{3}$, and $10^{-36} \mathrm{esu}$.

${ }^{b} \Delta \hat{\alpha}(\mathrm{C}-\mathrm{X})=\left(\hat{\alpha}_{41}-\hat{\alpha}_{1}\right)$ for a $\mathrm{C}-\mathrm{X}$ bond, derived from $\mathrm{CX}_{4}$ Raman intensity data ${ }^{15}$ (preferred) or theory.

c $\hat{\gamma}(\mathrm{C}-\mathrm{X})=\gamma\left(\mathrm{CX}_{4}\right) / 4$, derived from preferred values of $\gamma$ for $\mathrm{CX}_{4}$ molecules in Table II.

${ }^{d}$ Estimate based on infrared intensity data [I. M. Mills, Mol. Phys. 1, 107 (1958); R. E. Hiller and J. W. Straley, J. Mol. Spectrosc. 5, $24(1960)]$ with sense of polarization undetermined.

'Derived from the electric octopole moment of $\mathrm{CH}_{4}\left(10^{34} \Omega\right.$ $=1.9 \pm 0.4$ esu, from Ref. 16) by means of a bond model (A. D. Buckingham, Physical Chemistry, edited by D. Henderson (Academic, New York, 1970), Vol. 4, p. 383] consisting of four tetrahedrally disposed dressed point dipoles $\hat{\mu}(\mathrm{C}-\mathrm{H})$ located at a distance $R(\mathrm{C}-\mathrm{H})=1.1 \AA$ from the molecular center.

${ }^{2} \hat{\alpha}(\mathrm{C}-\mathrm{X})=\alpha^{\omega}\left(\mathrm{CX}_{4}\right) / 4$, derived from preferred values of $\alpha^{\omega}$ for $C X_{4}$ molecules in Table $I$.

Theoretical estimate from A. T. Amos and R. J. Crispin, J. Chem. Phys. 63, 1890 (1975).

${ }^{\mathrm{h}}$ Based on Raman intensity data from W. F. Murphy, W. Holzer, and H. J. Bernstein, Appl. Spectrosc. 23, 211 (1969).

${ }^{1}$ Based on Raman intensity data from S. Montero and D. Bermejo, Mol. Phys. 32, 1229 (1976).

Inf rared intensity data do not yield physically unambiguous estimates of $\hat{\mu}(\mathrm{C}-\mathrm{F})$ and $\hat{\mu}(\mathrm{C}-\mathrm{C} 1)$; see I for details.

dressed electrical properties determine the observed molecular properties. Our aim is to select a set of bare bond parameters which best reproduce a broad range of experimental data for the set of 12 halogenated methane molecules listed in Tables I and II. We now briefly review the relationship between dressed and bare electric tensors derived in I and then describe the process of selecting bare parameters to fit the experimental data.

We consider only the case of properties involving static electric fields, which offers simplicity in terms of the number and symmetry of the electric tensors. Quantities measured using optical fields are in general more accessible than static properties and are assumed to provide sufficiently accurate estimates of the static properties for our purpose. Expressions for molecular observables determined with optical fields are in principle far more complicated (and require more parameters) then those in the static limit, as was demonstrated in $\mathrm{I}$.

The field-dependent electric dipole moment $\mu_{i}(E)$ of the $i$ th bond can be written either in terms of the applied electric field $\mathrm{E}$ and dressed bond tensors:

$$
\mu_{i}(E)=\hat{\mu}_{i}+\hat{\alpha}_{i} E+\hat{\beta}_{i} E^{2}+\hat{\gamma}_{i} E^{3}+\cdots,
$$

or in terms of the local electric field $\mathrm{E}_{i}$ and bare bond tensors:

$$
\mu_{i}(\mathrm{E})=\mu_{i}+\alpha_{i} \mathrm{E}_{i}+\beta_{i} \mathrm{E}_{i}^{2}+\gamma_{i} \mathrm{E}_{i}^{3}+\cdots .
$$

The relationship between local and applied fields is ${ }^{19}$ :

$$
\mathrm{E}_{i}=\mathrm{E}+\sum_{j \neq i} \mathrm{~T}_{i j} \mu_{j}(\mathrm{E}) \equiv \mathrm{E}+\langle\mathrm{T} \cdot \mu(\mathrm{E})\rangle_{i},
$$

where $T_{i j}$ is given ${ }^{20}$ by

$$
\mathrm{T}_{i j}=\mathrm{T}_{j i}=\left(3 \mathrm{R}_{i j} \mathrm{R}_{i j}-R_{i j}^{2} 1\right) R_{i j}^{-5},
$$

in which $\mathbf{R}_{i j}$ is the vector joining the active centers of bonds $i$ and $j$ and 1 is a unit matrix.

Combination of Eqs. (3)-(6) yields a set of equations for the dressed tensors. These equations appeared in I as Eqs. (10)-(13) and are repeated here in a form which emphasizes similarities between the various equations:

$$
\begin{aligned}
& \hat{\mu}_{i}=\alpha_{i}^{\prime}\langle\mathrm{T} \cdot \hat{\mu}\rangle_{i}+\mu_{i}^{\prime}, \\
& \hat{\alpha}_{i}=\alpha_{i}^{\prime}\langle\mathrm{T} \cdot \hat{\alpha}\rangle_{i}+\alpha_{i}^{\prime}, \\
& \hat{\beta}_{i}=\alpha_{i}^{\prime}\langle\mathrm{T} \cdot \hat{\beta}\rangle_{i}+\beta_{i}^{\prime}, \\
& \hat{\gamma}_{i}=\alpha_{i}^{\prime}\langle\mathrm{T} \cdot \hat{\gamma}\rangle_{i}+\gamma_{i}^{\prime},
\end{aligned}
$$

where

$$
\begin{aligned}
& \mu_{i}^{\prime}=\mu_{i}-\beta_{i}\langle\mathrm{~T} \cdot \hat{\mu}\rangle_{i}^{2}-2 \gamma_{i}\langle\mathrm{~T} \cdot \hat{\mu}\rangle_{i}^{3}, \\
& \alpha_{i}^{\prime}=\alpha_{i}+2 \beta_{i}\langle\mathrm{~T} \cdot \hat{\mu}\rangle_{i}+3 \gamma_{i}\langle\mathrm{~T} \cdot \hat{\mu}\rangle_{i}^{2}, \\
& \beta_{i}^{\prime}=\left(\beta_{i}+3 \gamma_{i}\langle\mathrm{~T} \cdot \hat{\mu}\rangle_{i}\right)\left(1+\langle\mathrm{T} \cdot \hat{\alpha}\rangle_{i}\right)^{2}, \\
& \gamma_{i}^{\prime}=2\left(\beta_{i}+3 \gamma_{i}\langle\mathrm{~T} \cdot \hat{\mu}\rangle_{i}\right)\left(1+\langle\mathrm{T} \cdot \hat{\alpha}\rangle_{i}\right)\langle\mathrm{T} \cdot \hat{\beta}\rangle_{i}+\gamma_{i}\left(1+\langle\mathrm{T} \cdot \hat{\alpha}\rangle_{i}\right)^{3} .
\end{aligned}
$$

As in $I$, we have introduced the simplification of truncating the series expansions of Eqs. (3) and (4) after the terms involving $\hat{\gamma}$ or $\gamma$. Experimental data on higherorder hyperpolarizabilities are, in any case, not available.

It may be noted that Eqs. (7) $-(10)$ can be solved for the dressed tensors, as follows:

$$
\begin{aligned}
& \hat{\mu}_{i}=Q^{-1} \mu_{i}^{\prime}, \\
& \hat{\alpha}_{i}=Q^{-1} \alpha_{i}^{\prime}, \\
& \hat{\beta}_{i}=Q^{-1} \beta_{i}^{\prime}, \\
& \hat{\gamma}_{i}=Q^{-1} \gamma_{i}^{\prime},
\end{aligned}
$$

where schematically (i.e., omitting tensor suffixes and the sum over bonds implicit ${ }^{19}$ in our \langle\rangle notation) the matrix $Q$ is defined by

$$
Q=1-\alpha^{\prime} T \text {. }
$$

The computations based on the above equations consist of the following sequence:

(i) Characterize molecular geometry in terms of the bond angles measured for each molecule and an average bond length $\mathrm{R}(\mathrm{C}-\mathrm{X})$ for each bond type (see Table IV);

(ii) select factors $f(\mathrm{C}-\mathrm{X})$, such that the tensor properties of a given bond type are ascribed to an active center located at a distance of $f(\mathrm{C}-\mathrm{X}) \mathrm{R}(\mathrm{C}-\mathrm{X})$ from the 
carbon nucleus, and thence calculate the $T_{i s}$ matrices;

(iii) select initial values for the 24 bare bond parameters;

(iv) set $\hat{\mu}_{i}=0$ initially;

(v) evaluate $\mu_{i}^{\prime}$ and $\alpha_{i}^{\prime}$ from Eqs. (11) and (12);

(vi) evaluate $Q^{-1}$ from Eq. (19);

(vii) evaluate an updated estimate of $\hat{\mu}$ from Eq. (15);

(viii) if $\hat{\mu}_{i}$ differs by more than $10^{-5} \mathrm{D}$ from the righthand side of Eq. (7), reiterate steps (v)-(vii);

(ix) evaluate $\hat{\alpha}_{i}$ from Eq. (16);

(x) evaluate $\beta_{i}^{\prime}$ and $\hat{\beta}_{i}$ from Eqs. (13) and (17);

(xi) evaluate $\gamma_{i}^{\prime}$ and $\hat{\gamma}_{i}$ from Eqs. (14) and (18);

(xii) evaluate molecular observables using the dressed bond parameters calculated in steps (vii) $-(\mathrm{xi})$ and the molecular geometry from step (i);

(xiii) perform a nonlinear least-square fit of calculated properties to the preferred values using (uncertainty of preferred value) ${ }^{-2}$ as a weighting factor, to yield improved values of the bare bond parameters;

(xiv) repeat steps (iv)-(xiii) until the values of the bare bond parameters have stabilized.

With regard to the fitting procedure of step (xiii), it should be noted that it is necessary to compute the first derivative of each observable parameter with respect to each bare parameter; this task accounts for a substantial proportion of the processing time.

The calculations are simplified by judicious choice of coordinate systems and by noting that there are no more than two dissimilar bonds in any one of the molecules considered. Equations (7) $-(10)$ must include a sufficient number of dressed tensor components to determine the molecular observables and any additional components which interact with these. The dimensionalities so determined are:

$\begin{array}{lrrrr} & \hat{\mu} & \hat{\alpha} & \hat{\beta} & \hat{\gamma} \\ \mathrm{CX}_{4} & 1 & 4 & 1 & 4 \\ \mathrm{CXY}_{3} & 3 & 9 & 3 & 9 \\ \mathrm{CX}_{2} \mathrm{Y}_{2} & 4 & 10 & 4 & 10 .\end{array}$

The similarities between the $\hat{\mu}$ and $\hat{\boldsymbol{\beta}}$ calculations and between the $\hat{\alpha}$ and $\hat{\gamma}$ calculations are apparent. It is interesting to note that the polarizability of part of an interacting system need not be symmetric unless so required by the local symmetry of that part.

Eight bare parameters are considered for each bond type, this being the full number appropriate to the $C_{\infty v}$ symmetry of the bare bond. For a given bond $\mathrm{C}-\mathrm{X}$, we assign an axis $z$ which is taken to be the symmetry axis of the bare bond and to be directed out from the central $\mathrm{C}$ atom. A set of bare bond parameters is then defined as follows:

$$
\mu=\mu_{z} \text {, }
$$

TABLE IV. Molecular geometry for halogenated methane molecules. ${ }^{\text {a }}$

\begin{tabular}{llll}
\hline $\mathrm{C}-\mathrm{X}$ bond & $\theta(\mathrm{XCX})$ in $\mathrm{CX}_{3} \mathrm{Y}$ & $\theta(\mathrm{XCX})$ in $\mathrm{CX}_{2} \mathrm{Y}_{2}$ & $R(\mathrm{C}-\mathrm{X}) / \AA$ \\
\hline $\mathrm{C}-\mathrm{H}$ & $110.5^{\circ}, \mathrm{Y}=\mathrm{F}$ & $112.0^{\circ}, \mathrm{Y}=\mathrm{F}$ & 1.10 \\
& $110.9^{\circ}, \mathrm{Y}=\mathrm{Cl}$ & $112.0^{\circ}, \mathrm{Y}=\mathrm{Cl}$ & \\
$\mathrm{C}-\mathrm{F}$ & $108.8^{\circ}, \mathrm{Y}=\mathrm{H}$ & $108.4^{\circ}, \mathrm{Y}=\mathrm{H}$ & 1.36 \\
& $108.6^{\circ}, \mathrm{Y}=\mathrm{Cl}$ & $109.5^{\circ}, \mathrm{Y}=\mathrm{Cl}$ & \\
$\mathrm{C}-\mathrm{Cl}$ & $110.9^{\circ}, \mathrm{Y}=\mathrm{H}$ & $111.8^{\circ}, \mathrm{Y}=\mathrm{H}$ & 1.77 \\
& $111.5^{\circ}, \mathrm{Y}=\mathrm{F}$ & $108.5^{\circ}, \mathrm{Y}=\mathrm{F}$ & \\
\hline
\end{tabular}

${ }^{2} \mathrm{XCX}$ bond angles and average $\mathrm{C}-\mathrm{X}$ bond lengths are taken from L. E. Sutton et al., Tables of Interatomic Distances and Configuration in Molecules and Ions (Chemical Society, London, 1958); Interatomic Distances Supplement (Chemical Society, London, 1965).

$\alpha=\left(2 \alpha_{1}+\alpha_{11}\right) / 3=\left(\alpha_{x x}+\alpha_{y y}+\alpha_{z z}\right) / 3$,

$\Delta \alpha=\left(\alpha_{11}-\alpha_{\perp}\right)=\left(2 \alpha_{z z}-\alpha_{x x}-\alpha_{y y}\right) / 2$,

$\beta_{\perp}=\beta_{x x z}=\beta_{y y z}$ (and other permutations of $x x z$ or $y y z$ ),

$\beta_{11}=\beta_{z z z}$,

$\gamma_{1}=\gamma_{28 z \varepsilon}$

$\gamma_{2}=\gamma_{x x \& \varepsilon}=\gamma_{y y \& \varepsilon}$

(and other permutations of $x x z z$ or $y y z z$ ),

$\gamma_{3}=\gamma_{x x x x}=\gamma_{y y y y}=3 \gamma_{x x y y}$

(and other permutations of $x x y y$ ).

The above set of parameters is sufficient only in the static limit, where full spatial permutation symmetry holds. It should be reemphasized that our model is constructed in the static limit with experimental optical data accepted for input as an adequate approximation to static data.

It can be anticipated that not all of the above 24 bare bond parameters (eight for each of $\mathrm{C}-\mathrm{H}, \mathrm{C}-\mathrm{F}$, and $\mathrm{C}-\mathrm{Cl}$ ) will be well determined by the set of molecular observables listed in Tables I and II. This can be seen in extreme form in the case of a molecular model with tetrahedral bond angles and no interactions (BAA), for which only 12 linear combinations of the bare bond parameters can be determined by fitting to the molecular observables. For instance, the molecular electric dipole moments can be expressed in this tetrahedral BAA model in terms of two linear combinations of bare bond dipoles, such as $[\mu(\mathrm{C}-\mathrm{F})-\mu(\mathrm{C}-\mathrm{H})]$ and $[\mu(\mathrm{C}-\mathrm{Cl})-$ $\mu(\mathrm{C}-\mathrm{H})]$, so that the individual values of $\mu(\mathrm{C}-\mathrm{X})$ are undetermined. It follows that, in the ISM scheme with experimentally measured (nontetrahedral) bond angles, there are linear combinations of bare bond parameters determined only by deviations from tetrahedral symmetry and by details of the interactions. Such linear combinations are likely to be poorly determined by fitting to molecular observables alone. Fortunately, the limited amount of indirect experimental bond data (see Table III) combines with the molecular data to ensure that all $\mu$ and $\alpha$ parameters are well determined in the model. However, only two of six bare $\beta$ parameters and three of nine bare $\gamma$ parameters are, in this sense, well 
determined by the fit and the details of these parameter values should be viewed in this context. The computer program includes the facility for clamping any parameter(s) to a predetermined value and this has proved useful in investigating the change in quality of fit as $\gamma$ parameters were restrained from going negative. Details are discussed in Sec. IV.

The computational procedures outlined above were performed on a PDP $10 / \mathrm{KA}$ computer. The iterative calculation of $\hat{\mu}$ and $\mu^{\prime}$ typically takes three cycles to come within $10^{-5} \mathrm{D}$ of the correct value. Four cycles of the overall fitting procedure are typically necessary to attain stable values of the bare parameters, this requiring about ten minutes of processing time. Starting values of bare parameters were chosen [see step (iii) of the procedure outlined above] either on the basis of bond additivity considerations or from a preceding fitting cycle. This choice does not materially affect the final outcome of the fit and there has been no evidence of multiple minima in the $\chi^{2}$ quality factor. Other conditions which vary from one computation to another will be indicated as those computations are discussed in the following section.

\section{RESULTS AND DISCUSSION}

A variety of computations, based on the ISM and BAA schemes and applied to the 12 halogenated methane molecules of interest, have been performed. We describe and display the results of a particular ISM fit and then compare and contrast certain features of the other calculations. Each calculation is distinguished by three conditions which may vary from one calculation to another: choice of active center for each bond type, and hence scaling of the interaction contributions; selection of observable data to be included in the fit; and specification of those bare bond parameters which are free to vary.

In the central ISM calculation, the parameters $f(\mathrm{C}-\mathrm{X})$ which specify the active center have been chosen to be
1.0 for all three bond types. This choice differs from that of $\mathrm{I}$ in the case of $f(\mathrm{C}-\mathrm{H})$, which was previously taken to be 0.5 on the basis of the early work of Smyth and McAlpine. ${ }^{21}$ The larger value of $f(\mathrm{C}-\mathrm{H})=1.0$ now adopted is necessary to avoid physically unacceptable divergences of the polarizability, in a manner previous ly characterized by Applequist et al. ${ }^{22}$ Values of dressed bond properties $\hat{\mu}(\mathrm{C}-\mathrm{X})$ and $\Delta \hat{\alpha}(\mathrm{C}-\mathrm{X})$ in the appropriate $\mathrm{CX}_{4}$ molecules have been selected from Table III as follows: $\hat{\mu}(\mathrm{C}-\mathrm{H})=+0.30(6) \mathrm{D} ; \Delta \hat{\alpha}(\mathrm{C}-\mathrm{H})=0.28(3) \mathrm{A}^{3}$; $\Delta \hat{\alpha}(\mathrm{C}-\mathrm{F})=0.56(5) \AA^{3} ; \Delta \hat{\alpha}(\mathrm{C}-\mathrm{Cl})=1.89(20) \hat{A}^{3}$, where uncertainties are indicated in parentheses. These values, together with the preferred values of molecular observables from Tables I and II, provide 58 pieces of data for the nonlinear least-square fitting procedure used to refine the set of 24 bare bond parameters. Optimum final values of bare bond parameters generated by this central ISM fit are summarized in part $A$ of Table $V$.

Corresponding results for a parallel BAA computation are displayed in part $B$ of Table $V$. This BAA fit is achieved by using the ISM program with the $f(\mathrm{C}-\mathrm{X})$ parameters set very large so that interactions are negligible. In the absence of interactions, it is meaningful to fit only a single $\beta$ parameter and a single $\gamma$ parameter for each bond type, as indicated in Table $V$. Hence the BAA calculation fits 15 bare bond parameters to $58 \mathrm{ob}-$ servables.

It should not be inferred that the bare bond parameters determined by either BAA or ISM represent a unique or physically definitive set of values. They can be regarded, however, as a valid self-consistent set of bare bond parameters given the arbitrary choice of $f(C-X)$ to locate the active centers, the preferred values of molecular and dressed bond observables used in the fit, the statistical weighting procedure, the truncation of the hyperpolarizability series, and the various conceptual approximations inherent in the model. With this caveat, we present also optimum values of dressed bond and molecular electric tensor properties obtained from the ISM fitting procedure. These are tabulated in the Ap-

TABLE V. Electric tensor parameters for bare bonds, calculated from ISM (A) and BAA (B) fitting procedures.

\begin{tabular}{|c|c|c|c|c|c|c|c|c|}
\hline $\begin{array}{l}\text { A. } \\
\text { Bond }\end{array}$ & $\mu(\mathrm{C}-\mathrm{X})^{\mathrm{b}}$ & $\alpha(\mathrm{C}-\mathrm{X})$ & $\Delta \alpha(\mathrm{C}-\mathrm{X})$ & $\beta_{1}(C-X)$ & $\beta_{11}(\mathrm{C}-\mathrm{X})$ & $\gamma_{1}(\mathrm{C}-\mathrm{X})$ & $\gamma_{2}(\mathrm{C}-\mathrm{X})$ & $\gamma_{3}(\mathrm{C}-\mathrm{X})$ \\
\hline $\mathrm{C}-\mathrm{H}$ & $0.43(8)$ & $0.619(8)$ & $-0.114(30)$ & $-0.036(18)$ & $-0.038(31)$ & $0.17(2)$ & $-.0 .02(2)$ & $-0.01(3)$ \\
\hline$C-F$ & $-0.91(8)$ & $0.636(9)$ & $0.123(36)$ & $0.027(19)$ & $0.160(31)$ & $0.24(4)$ & $-0.14(3)$ & $0.18(4)$ \\
\hline $\mathrm{C}-\mathrm{Cl}$ & $-0.81(12)$ & $2.435(20)$ & $0.444(45)$ & $-0.206(27)$ & $0.106(37)$ & $0.30(5)$ & $0.04(7)$ & $0.19(14)$ \\
\hline $\begin{array}{l}\text { B. } \\
\text { Bond }\end{array}$ & $\mu(\mathrm{C}-\mathrm{X})^{\mathrm{b}}$ & $\alpha(\mathrm{C}-\mathrm{X})$ & $\Delta \alpha(\mathrm{C}-\mathrm{X})$ & \multicolumn{2}{|c|}{$(3 / 5)\left[\beta_{11}+2 \beta_{1}\right](C-X)^{c}$} & \multicolumn{3}{|c|}{$(1 / 5)\left[\gamma_{1}+4 \gamma_{2}+8 \gamma_{3} / 3\right](C-X)^{d}$} \\
\hline $\mathrm{C}-\mathrm{H}$ & $-0.16(6)$ & $0.647(4)$ & $0.309(24)$ & \multicolumn{2}{|c|}{$-0.155(77)$} & \multicolumn{3}{|c|}{$0.066(1)$} \\
\hline $\mathrm{C}-\mathrm{F}$ & $-1.93(5)$ & $0.720(4)$ & $0.531(27)$ & \multicolumn{2}{|c|}{$-0.016(74)$} & \multicolumn{3}{|c|}{$0.021(1)$} \\
\hline $\mathrm{C}-\mathrm{Cl}$ & $-1.57(6)$ & $2.576(19)$ & $2.088(33)$ & \multicolumn{2}{|c|}{$-0.213(75)$} & \multicolumn{3}{|c|}{$0.317(3)$} \\
\hline
\end{tabular}

${ }^{\mathrm{a}}$ The components of the bare bond electric tensors $\mu(\mathrm{C}-\mathrm{X}), \alpha(\mathrm{C}-\mathrm{X}), \beta(\mathrm{C}-\mathrm{X})$, and $\gamma(\mathrm{C}-\mathrm{X})$ are defined in Eqs. (20)-(27) and are tabulated in units of $D\left(10^{-18} \mathrm{esu}\right), \AA^{3}\left(10^{-24} \mathrm{esu}\right), 10^{-30} \mathrm{esu}$, and $10^{-36} \mathrm{esu}$, respectively. Details of the conditions under which the fitting procedures were applied are given in the text. Standard deviations of the fitted parameters are indicated in parentheses.

${ }^{b} \mathrm{~A}$ positive value of $\mu(\mathrm{C}-\mathrm{X})$ implies the sense of polarization $\mathrm{C}^{-}-\mathrm{X}^{+}$(see text).

${ }^{\circ}$ Corresponding values from the ISM are: $\mathrm{C}-\mathrm{H},-0.066 ; \mathrm{C}-\mathrm{F}, 0.128 ; \mathrm{C}-\mathrm{Cl},-0.184$.

${ }^{d}$ Corresponding values from the ISM are: $\mathrm{C}-\mathrm{H}, 0.013$; $\mathrm{C}-\mathrm{F}, 0.038 ; \mathrm{C}-\mathrm{Cl}, 0.191$. 


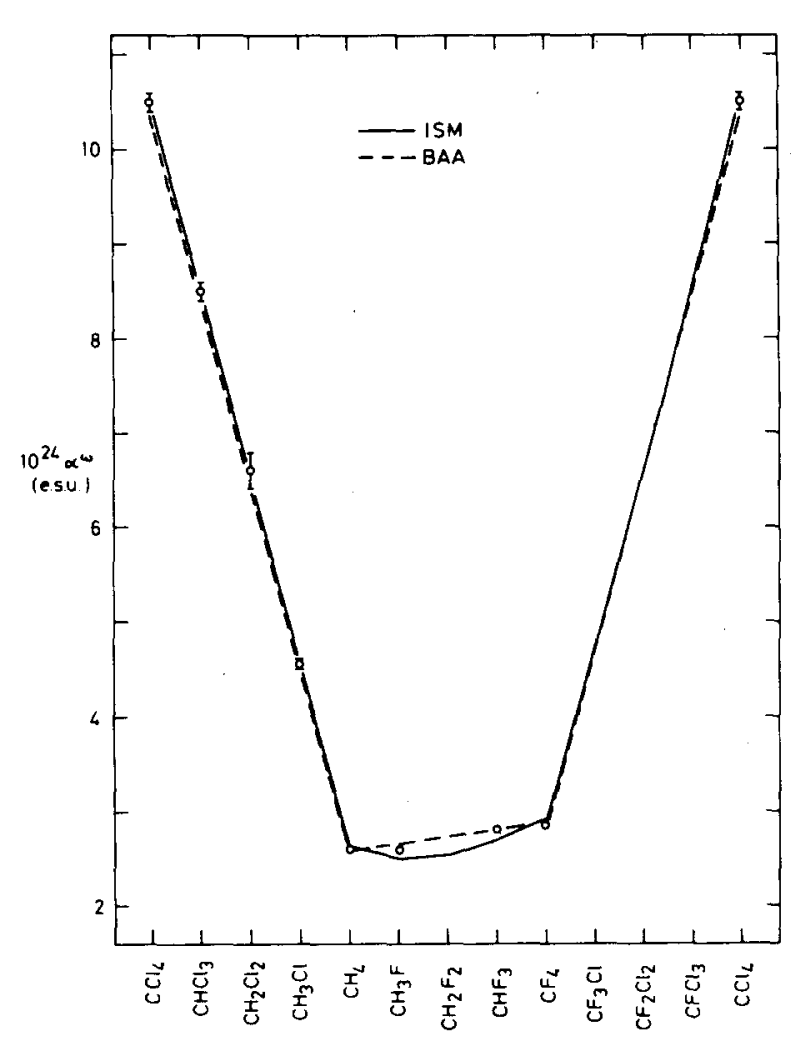

FIG. 1. Isotropic optical polarizabilities $\alpha^{\omega}$ for the halogenated methanes. Preferred experimental data are plotted as circles with associated error flags. Points resulting from an ISM fit with bare bond parameters from part $A$ of Table $V$ are displayed by linking them with a solid line. A corresponding BAA fit, based on part $B$ of $T$ able $V$, is indicated with a broken line.

pendix to this paper and may provide a useful set of reference data for potential extensions of the ISM model into such areas as prediction of spectroscopic intensities or of intermolecular forces.

A graphical comparison of the experimental molecular observables with those calculated by the ISM and BAA procedures is presented in Figs. 1-6. Figures 1 and 2 refer to the isotropic molecular observables $\alpha^{\omega}$ and $\gamma$, which are known ${ }^{1}$ to vary from molecule to molecule in a manner consistent with the BAA model. It is apparent from Figs. 1 and 2 that the ISM scheme provides at least as good a fit to the $\alpha^{\omega}$ and $\gamma$ data, despite the fact that interactions contribute appreciably. It follows that, although linear trends in isotropic properties such as $\alpha^{\omega}$ and $\gamma$ are a necessary consequence of bond additivity, they are by no means sufficient evidence that interactions are negligible. For example, according to the ISM calculations (Table $\mathrm{V}$ and Appendix), only $56 \%$ of $\gamma$ for the $\mathrm{CCl}_{4}$ molecule comes directly from the bare $\gamma$ parameters for the $\mathrm{C}-\mathrm{Cl}$ bond, the remainder arising from essentially nonadditive interaction contributions. The corresponding direct contributions to $\gamma$ for $\mathrm{CH}_{4}$ and $\mathrm{CF}_{4}$ are 20 and $173 \%$. The direct contributions to $\alpha^{\omega}$ for $\mathrm{CCl}_{4}, \mathrm{CH}_{4}$, and $\mathrm{CF}_{4}$ amount to 92,94 , and $87 \%$, respectively. It is doubtful that the finer details of the ISM fits portrayed in Figs. 1 and 2 for the $\mathrm{CH}_{n} \mathrm{~F}_{4-n}$ molecules are physically significant.
The second pair of observables (Figs. 3 and 4) is $\mu$ and $\beta$, each of which transforms as a vector. Here the ISM scheme is markedly superior to the BAA model in fitting the molecular data, particularly for $\beta$. Even so, the electric dipole moment data for the $\mathrm{CH}_{n} \mathrm{Cl}_{4-n}$ molecules are not well represented by either model, constituting a problem which has resisted interpretation in terms of a bond model for almost 50 years. ${ }^{21}$ It would appear that, even after electrostatic interactions between bonds have been taken into account, there remain other factors such as steric interference effects (only partially accounted for by using experimental bond angles) which degrade the transferability of the bond parameters. This problem apart, the inclusion of inductive effects by means of the ISM scheme enables the observed $\mu$ and $\beta$ data to be fitted adequately, again illustrating the significance of interactions in determining molecular electric tensor properties. It should also be noted that the BAA model provides a much poorer fit, $-0.16(6) \mathrm{D}$, to the preferred dressed electric dipole moment, $0.30(6) \mathrm{D}$, of a $\mathrm{C}-\mathrm{H}$ bond in $\mathrm{CH}_{4}$ than does the ISM scheme, for which $\hat{\mu}(\mathrm{C}-\mathrm{H})=0.29(6) \mathrm{D}$.

Figures 5 and 6 display results for the two anisotropic polarizability properties $\rho$ and $\left(\alpha_{z Z}^{\omega}-\alpha^{\omega}\right)$. Here the ISM is marginally more successful than the BAA in fitting the available data. Both models provide an adequate fit to the values of $\Delta \hat{\alpha}(C-X)$ in $\mathrm{CX}_{4}$ (see footnote $\mathrm{d}$ of Table VII in the Appendix).

When viewed overall, the ISM scheme is substantially more successful than the BAA model in correlating the experimental data available. This is reflected in the

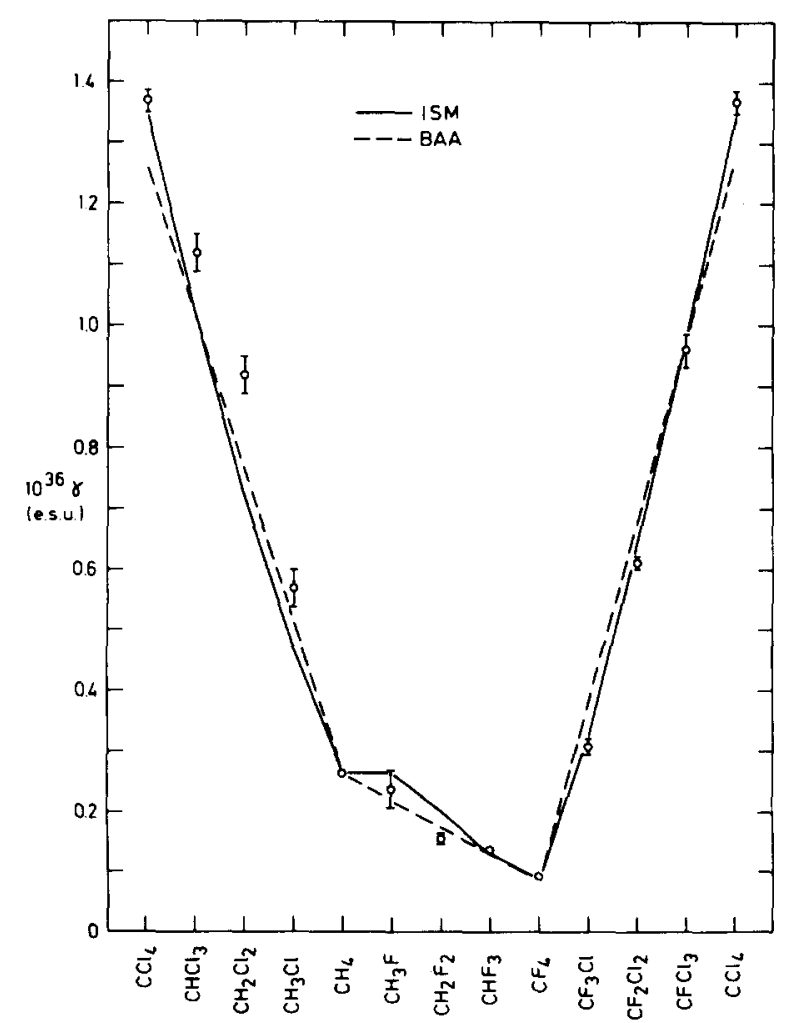

FIG. 2. Hyperpolarizabilities $\gamma$ for the halogenated methanes. See caption to Fig. 1 for further details. 


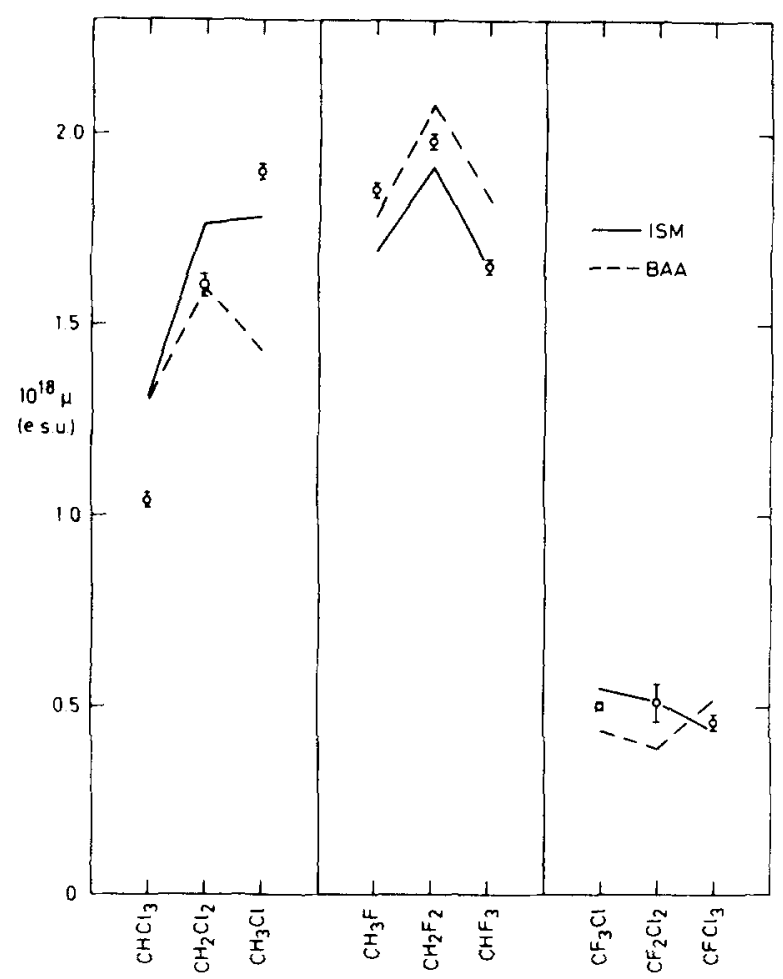

FIG. 3. Electric dipole moments $\mu$ for the halogenated methanes See caption to Fig. 1 for further details.

reduced $\chi^{2}$ parameter ${ }^{23}$ for the two fits: 18 for the ISM and 47 for BAA. This is perhaps not surprising in view of the greater flexibility of the ISM fitting procedure. In addition, there are sufficient instances, in which bare

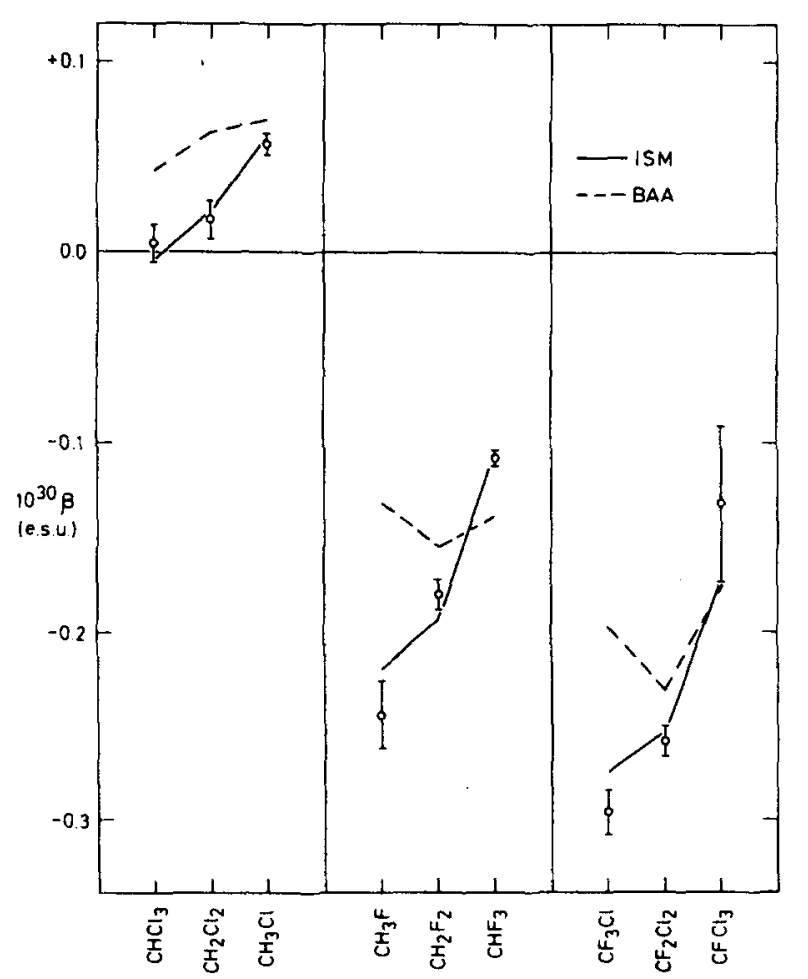

FIG. 4. Hyperpolarizabilities $\beta$ for the halogenated methanes. See caption to Fig. 1 for further details.

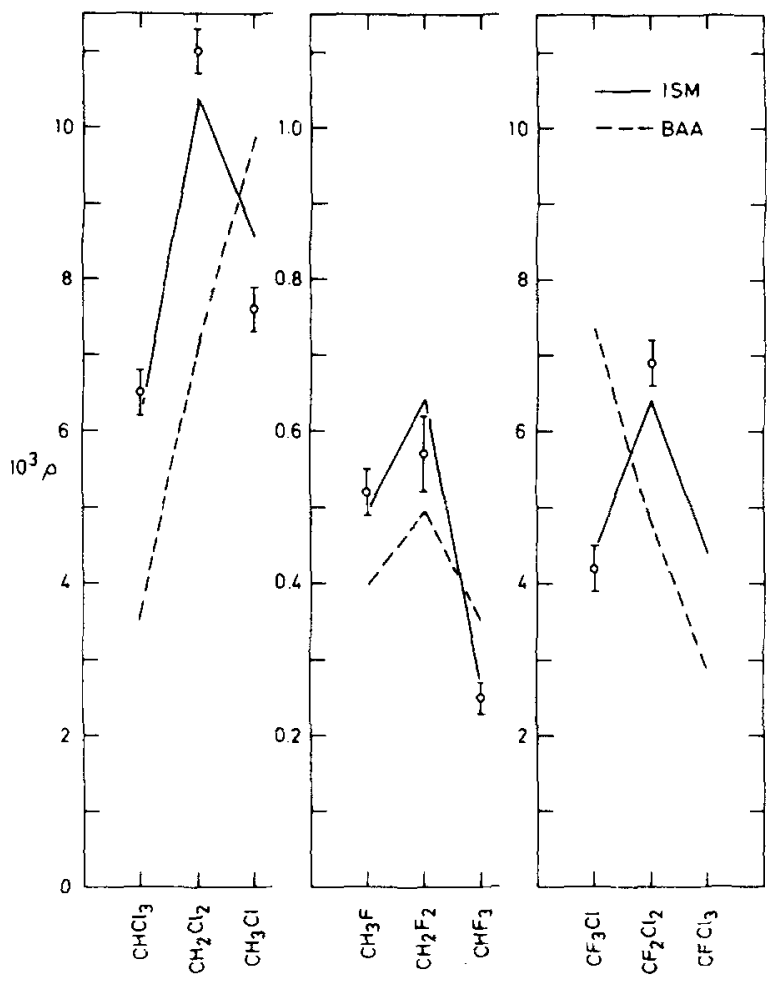

FIG. 5. Depolarization ratios $\rho$ for the halogenated methanes. See caption to Fig. 1 for further details.

and dressed bond parameters derived from the ISM appear physically more reasonable than those from the $\mathrm{BAA}$, to establish a preference for the former scheme.

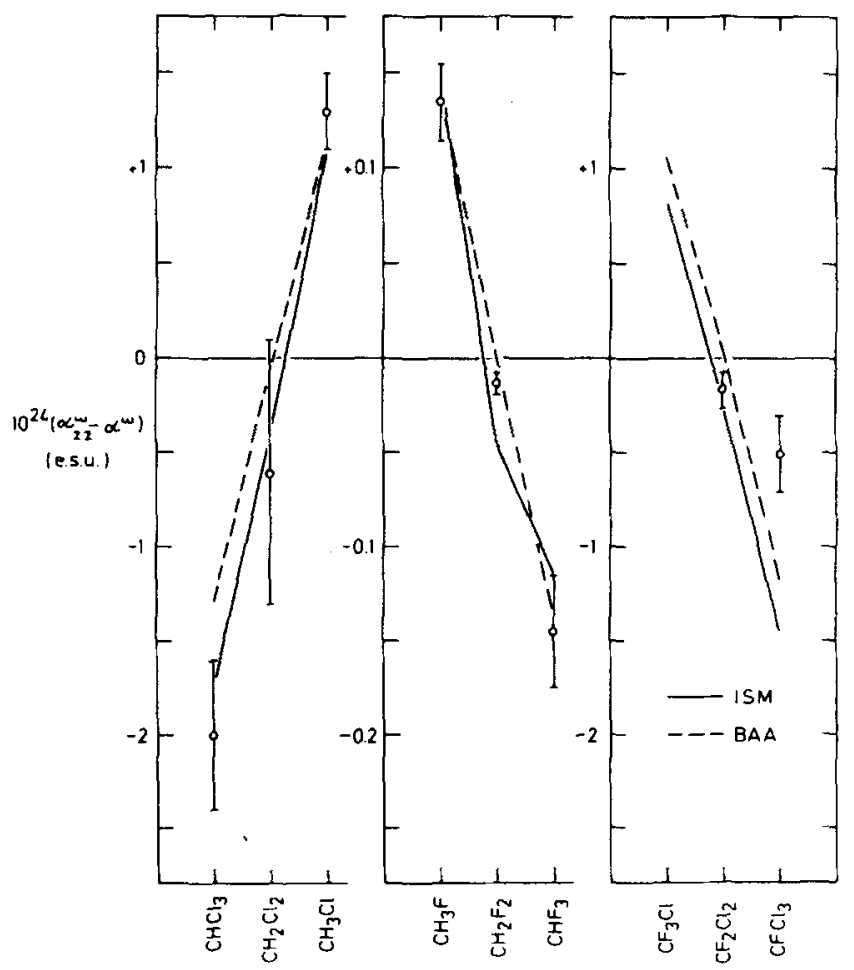

FIG. 6. Polarizability anisotropies $\left(\alpha_{Z Z Z}^{\omega}-\alpha^{\omega}\right)$ for the halogenated methanes. See caption to Fig. 1 for further details. 
Of the bare bond parameters determined by the ISM and listed in part $A$ of Table $V$, the only values which might be considered physically unexpected are the negative values of several $\gamma(\mathrm{C}-\mathrm{X})$ components. Additional computations with these $\gamma$ parameters clamped to zero generated similar fits with $\chi^{2}$ changing only marginally. This situation arises because there are three bare $\gamma$ parameters for each bond type, but only one (isotropic) $\gamma$ observable per molecule. Further examination of Table $\mathrm{V}$ shows that polarizability anisotropies $\Delta \alpha(\mathrm{C}-\mathrm{X})$ from the ISM scheme are substantially smaller (by a factor of 3-5) than those from the BAA model, indicating that nonadditive contributions to molecular polarizability anisotropies are appreciable and accounting for irregular trends in molecular observables. ${ }^{1}$ Analogous remarks have already been made in relation to the vector properties $\mu$ and $\beta$.

A second set of ISM computations with modified active center locations $[f(\mathrm{C}-\mathrm{F})=f(\mathrm{C}-\mathrm{Cl})=1.2$ and $f(\mathrm{C}-\mathrm{H})=1.0]$ and other conditions as in the central ISM calculation has been performed to test the sensitivity of the model to variations in the range of interactions. The overall quality of this longer-range fit is comparable to that in the central ISM fit with all $f(C-X)=1.0$ $\left(\chi^{2}=19\right.$, compared to the previous value of 18$)$, but the two fits differ substantially in detail. For example, the values of bare parameters are all, with the exception of $\mu(\mathrm{C}-\mathrm{F})$ and $\mu(\mathrm{C}-\mathrm{Cl})$, increased in magnitude in the longer-range ISM calculation. The quality of the fit to individual molecular observables with the longer-range ISM scheme is comparable to that of the central ISM calculation in the case of $\mu, \alpha^{\omega}, \rho$, and $\left(\alpha_{z Z}^{\omega}-\alpha^{\omega}\right)$ but inferior in the case of the hyperpolarizability observables $\beta$ and $\gamma$, reflecting the strong effect which interactions play in determining the latter quantities. Undoubtedly the least favorable result of the ISM calculations at longer range is their failure to fit well the preferred dressed bond properties $\hat{\mu}(\mathrm{C}-\mathrm{H})$ and $\Delta \hat{\alpha}(\mathrm{C}-\mathrm{X})$ in $\mathrm{CX}_{4}$-type molecules. The values calculated are: $\hat{\mu}(\mathrm{C}-\mathrm{H})=+0.47 \mathrm{D} ; \Delta \hat{\alpha}(\mathrm{C}-\mathrm{H})=0.19 \AA^{3} ; \Delta \hat{\alpha}(\mathrm{C}-\mathrm{F})=0.41$ $\AA^{3} ; \Delta \hat{\alpha}(\mathrm{C}-\mathrm{Cl})=1.74 \AA^{3}$. The net standard deviation of this fit to the dressed bond parameters is about 2.5 times that for the central ISM calculation with $f(\mathrm{C}-\mathrm{X})$ $=1.0$, indicating that the longer-range ISM scheme yields less physically reasonable results. No attempt has been made to optimize the values of $f(\mathrm{C}-\mathrm{X})$ but it is clear, from the foregoing longer-range calculation and from divergences in the polarizability which occur at shorter range (as mentioned above), that such an optimum would not depart markedly from the condition adopted in the central ISM calculation, namely, all $f(C-X)=1.0$.

An additional ISM fit [with all $f(\mathrm{C}-\mathrm{X})=1.0$ ], from which the dressed bond parameters $\Delta \hat{\alpha}(\mathrm{C}-\mathrm{F})$ and $\Delta \hat{\alpha}(\mathrm{C}-\mathrm{Cl})$ were excluded, produced only a marginal change in $\chi^{2}$ (20, compared to 18 for the central ISM calculation) and in the bare bond parameters. The resulting predicted values of unfitted dressed bond polarizability anisotropies are $\Delta \hat{\alpha}(\mathrm{C}-\mathrm{F})=0.41 \AA^{3}$ and $\Delta \hat{\alpha}(\mathrm{C}-\mathrm{Cl})=2.03 \hat{\mathrm{A}}^{3}$, compared to the preferred values of $0.56(5)$ and $1.89(20)$, respectively. It follows that bond polarizability anisotropies available from Raman intensity measurements (see Table III) are relatively well determined by the ISM scheme, provided that one reference value of $\Delta \hat{\alpha}(\mathrm{C}-\mathrm{X})$ (in this case, that for $\mathrm{C}-\mathrm{H}$ ) is included in the fit; this demonstrates a close correlation between molecular polarizability data and Raman intensities.

The particularly detailed study ${ }^{7}$ of polarizability anisotropies for $\mathrm{CH}_{2} \mathrm{~F}_{2}$ provides a further test of the predictive capacity of the ISM approach. Because $\left(\alpha_{Z Z}^{\omega}-\alpha^{\omega}\right)$ is very small, the anisotropy $\left(\alpha_{X X}^{\omega}-\alpha_{Y Y}^{\omega}\right)$ is well determined in magnitude by the depolarization ratio $\rho$ and less well determined in sign by the rotational Raman spectrum (see footnote $y$ of Table I). The central ISM calculation is therefore constrained, through the fitting of $\rho$ for $\mathrm{CH}_{2} \mathrm{~F}_{2}$, to reproduce $\left|\left(\alpha_{X X}^{\omega}-\alpha_{Y Y}^{\omega}\right)\right|$ but the calculated sign of that quantity may be regarded as a prediction. The ISM prediction is $\left(\alpha_{X X}^{\dot{\omega}}-\alpha_{Y Y}^{\omega}\right)$ $=+0.28 \AA^{3}$, which is of the same sign as the preferred value $\left(\alpha_{X X}^{\omega}-\alpha_{Y Y}^{\omega}\right)=+0.291(15)$ (see Table I, footnote y). Attempts to fit the ISM to a negative value of $\left(\alpha_{X X}^{\omega}-\alpha_{Y Y}^{\omega}\right)$ yielded a very large value of $\chi^{2}$ and confirmed that the ISM-predicted positive sign is significant.

The only available molecular hyperpolarizability observable not included in the ISM fit is $\beta_{X^{*} Y^{*} z^{*}}$ for $\mathrm{CH}_{4}$ $\left(\beta_{X^{\prime} Y^{\prime} Z^{\prime}}\right.$ is defined in the coordinate system of Ref. 26 and is related to our $\beta$ by $\beta_{X^{\prime} Y^{\prime} Z^{\prime}}=-\sqrt{3} / 2 \beta_{z Z Z}$ ). This has been determined approximately by experiment ${ }^{24}$ to yield $10^{30} \beta_{X^{\prime} Y^{\prime} Z^{\prime}}= \pm 0.005 \mathrm{esu}$, which compares with recent theoretical values ${ }^{25-27}$ in the range -0.09 to +0.1 . The bare bond parameters listed in part $A$ of Table $\mathrm{V}$ have been used in an ISM calculation, yielding $10^{30} \beta_{X^{\prime} Y^{\prime} z^{\prime}}=+0.20\left(\mathrm{CH}_{4}\right),-0.91\left(\mathrm{CCl}_{4}\right),-0.76\left(\mathrm{CF}_{4}\right)$ esu. The value predicted for $\mathrm{CH}_{4}$ is much larger than the experimental value.

The usefulness of models such as ISM depends in part on the shortcomings of alternative, more rigorous approaches to molecular electric tensor properties. The current state of the art in $a b$ initio calculations yields reliable values of electric dipole moment and electronic contributions to the polarizability for small molecules, particularly diatomics and polyatomic hydrides of firstrow elements. However, the treatment of large molecules and of hyperpolarizabilities (even of small molecules) remains an area of theoretical and computational development in which agreement between theory and experiment is erratic and open to improvement. For example, within the last decade a number of coupled Hartree-Fock (CHF) calculations, some incorporating configuration interaction, have yielded the following results for the $\mathrm{CH}_{4}$ molecule: $\alpha^{0} / \AA^{3}=1.85,{ }^{25} 2.53,{ }^{28}$ $2.42,{ }^{26} 2.24,{ }^{27}$ compared with an experimental value (see Table I) of $2.59 ; 10^{30} \beta_{X^{\prime} X^{\prime} Z^{\prime}} / \mathrm{esu}=+0.094,{ }^{25}$ $-0.075,{ }^{28}-0.085,{ }^{27}$ compared with an approximate experimental value ${ }^{24}$ of \pm 0.005 . As a further instance, recent CHF computations ${ }^{28,29}$ of components of $\mu, \alpha$, $\beta$, and $\gamma$ for the HF molecule have yielded substantial agreement to within 20\%; unfortunately, this and most other diatomic hydrides are inaccessible to the majority of accurate experimental techniques. It is realistic to expect that the prospect of $a b$ initio calculations of comparable quality for the full range of molecules and prop- 
erties considered in this paper is, at best, remote. Bond models of the type presented in this paper serve to avoid the above mismatch of feasible theory and practical experiment and offer the only practical and generally applicable means for correlating and interpreting electric tensor properties for polyatomic molecules of moderate size.

Our ISM scheme is one of a number of models which have been devised in recent years to correlate molecular electric tensor properties by taking account of electrostatic interactions within the molecule. Notable in this regard are the atom dipole interaction models (ADIM) developed by Applequist et al. ${ }^{22,30}$ and Sundberg $^{31}$ to treat molecular polarizability and hyperpolarizabilities. Extensions of the ADIM have been made into Raman scattering, ${ }^{32}$ optical activity, ${ }^{33}$ and various other optical effects in relatively complex molecules. ${ }^{30,34}$ The ISM scheme represents the molecule as an assembly of bonds with associated electric tensor properties, rather than taking the inherently simpler but structurally less realistic approach of regarding molecules as an assembly of polarizable, isotropic atoms, as in the ADIM method and the early work of Silberstein. ${ }^{35}$ Both models have their advantages, but the more elaborate ISM scheme would appear to be more physically realistic in treating simple molecules such as the halogenated methanes.

\section{CONCLUSIONS}

It is inherent in a model such as ISM that the full quantum mechanical rigor of the $a b$ initio approach is sacrificed in the interest of simplicity and intuitive appeal. For example, steric congestion is only partially accounted for in ISM by the use of experimental bond angles, and the discrepancy in fitting $\mu$ for $\mathrm{CHCl}_{3}$ may be attributable to this omission. Even in the context of a classical electrostatic interaction model, we have not striven for full generality. This is evidenced by restriction to dipole interactions, localization of the active center, and termination of the hyperpolarizability contributions at $\gamma$. The goal has been the simplest possible model offering a fit to observed $\mu, \alpha, \beta$, and $\gamma$ data for the halog enated methanes which should be generally adequate and substantially improved with respect to the fit offered by BAA. We claim a good measure of success in pursuit of this goal.

There are a number of details of this implementation of ISM which while defensible are not unique: data selection, ignoring the frequency dependence of molecular properties, weighting of the fit, and choice of active center location. Consequently the bare and dressed bond parameters so derived are neither unique nor definitive but rather constitute a set of physically reasonable and self-consistent parameters which adequately represent the molecular properties considered and which might usefully be extended to calculations of spectroscopic quantities and of intermolecular forces.

A most important consideration in determining the performance of ISM is the degree to which bare parameters are determined directly by fitting to data rather than by interactions only or by deviations from tetra- hedral geometry (see discussion in Sec. III). If one bond $\Delta \hat{\alpha}$ and one bond $\hat{\mu}$ are included in the data, all $\mu$ and $\alpha$ parameters are directly determined while only five of $15 \beta$ and $\gamma$ parameters are directly determined. Several features of the results can be understood in this context: the fit is insensitive to clamping several bare $\gamma$ parameters to zero; the model is able to make good predictions for $\Delta \hat{\alpha}$ and $\left(\alpha_{X X}^{\omega}-\alpha_{Y Y}^{\omega}\right)$ but not for $\beta_{X^{\prime}} Y^{\prime} z^{\prime}$. Termination of the hyperpolarizability series at $\gamma$ may also contribute to the reduced reliability of ISM for predicting hyperpolarizabilities. It is to be expected that bare and dressed bond parameters will be more reliable in the case of $\mu$ and $\alpha$ than for $\beta$ and $\gamma$.

At the outset of this project (see I), it was well established that the molecular observables $\mu, \beta, \rho$, and $\left(\alpha_{z z}^{\omega}-\alpha^{\omega}\right)$ fail to conform to an interaction-free bond additivity model and hence that an ISM-style approach would be necessary in correlating the observables with a set of bond properties. In the case of the isotropic variables $\alpha^{\omega}$ (or $\alpha^{0}$ ) and $\gamma$, however, it was known that trends from one molecule to another were sufficiently linear to be well represented by simple BAA relationships. The success of BAA, here, has sometimes been interpreted as evidence that interbond electrostatic interactions in general are negligible in spite of simple arguments to the contrary. ${ }^{1}$ We have demonstrated that $\alpha$ continues to be well fitted when interactions are included in the model but that interactions conspire to make a small (typically 10\%) contribution. This situation is largely a consequence of the fact that the polarizability anisotropy $\Delta \alpha(C-X)$ of a given bond is typically much smaller than the isotropic part $\alpha(\mathrm{C}-\mathrm{X})$; it then follows from a Silberstein-type ${ }^{35}$ model that the leading interaction-dependent contributions to the isotropic molecular polarizability involve $\Delta \alpha(\mathrm{C}-\mathrm{X})$, rather than $\alpha(C-X)$, and are therefore small. $\gamma$ also continues to be well fitted in ISM and similar arguments can be applied to this case. $\gamma$ differs from $\alpha$, however, in that ISM results indicate a large interaction contribution. It is possible that this detailed feature of the $\gamma$ calculation is an artifact associated with the small fraction of bare bond $\gamma$ 's which are directly determined (see previous discussion).

Whatever the degree of success of ISM, and we believe this to be substantial, it should be pointed out that the calculations reported here represent a far more extensive implementation and testing of such a model than has previously been attempted. They therefore serve to demonstrate the scope, limitations, and advantages of the interacting bond model approach.

\section{ACKNOWLEDGMENTS}

We gratefully acknowledge helpful communications with M. P. Bogaard, R. S. Haines, M. L. Klein, and W. F. Murphy.

\section{APPENDIX: ISM CALCULATIONS OF DRESSED BOND AND MOLECULAR ELECTRIC TENSOR PROPERTIES}

In this Appendix we present the detailed results of the central ISM calculation, carried out under the following conditions: all $f(\mathrm{C}-\mathrm{X})=1.0$; preferred values of the 54 
TABLE VI. Dressed bond and molecular $\hat{\mu}$ and $\hat{\beta}$ parameters, from ISM calculations for halogenated methanes. ${ }^{2}$

\begin{tabular}{|c|c|c|c|c|c|c|}
\hline \multirow{2}{*}{$\begin{array}{l}\text { Molecule } \\
\mathrm{CX}_{n} \mathrm{Y}_{4-n}\end{array}$} & \multicolumn{4}{|c|}{$\begin{array}{c}\text { Dressed parameters for } \mathrm{C}-\mathrm{X} \text { (upper entry) and } \mathrm{C}-\mathrm{Y} \\
\text { (lower entry) bonds }{ }^{\mathrm{b}}\end{array}$} & \multicolumn{2}{|c|}{ Molecular observables } \\
\hline & $\overline{\hat{\mu}_{x}}$ & $\hat{\mu}_{z}$ & $\hat{\beta}_{x \neq 0}$ & $\hat{\beta}_{z 00}$ & $\mu$ & $\beta$ \\
\hline $\mathrm{CCl}_{4}$ & 0 & -0.519 & 0 & 0.036 & 0 & 0 \\
\hline $\mathrm{CHCl}_{3}$ & $\begin{array}{l}0 \\
-0.023\end{array}$ & $\begin{array}{r}0.569 \\
-0.731\end{array}$ & $\begin{array}{l}0 \\
0.052\end{array}$ & $\begin{array}{r}0.064 \\
-0.082\end{array}$ & 1.313 & -0.005 \\
\hline $\mathrm{CH}_{2} \mathrm{Cl}_{2}$ & $\begin{array}{l}-0.059 \\
-0.027\end{array}$ & $\begin{array}{r}0.481 \\
-0.965\end{array}$ & $\begin{array}{l}0.025 \\
0.062\end{array}$ & $\begin{array}{l}-0.032 \\
-0.193\end{array}$ & 1.763 & 0.022 \\
\hline $\mathrm{CH}_{3} \mathrm{Cl}$ & $\begin{array}{l}-0.064 \\
0\end{array}$ & $\begin{array}{r}0.389 \\
-1.235\end{array}$ & $\begin{array}{l}0.025 \\
0\end{array}$ & $\begin{array}{l}-0.128 \\
-0.293\end{array}$ & 1. 779 & 0.061 \\
\hline $\mathrm{CH}_{4}$ & 0 & $0.287^{d}$ & 0 & -0.223 & 0 & 0 \\
\hline $\mathrm{CH}_{3} \mathrm{~F}$ & $\begin{array}{l}-0.068 \\
0\end{array}$ & $\begin{array}{r}0.420 \\
-1.098\end{array}$ & $\begin{array}{l}0.021 \\
0\end{array}$ & $\begin{array}{r}-0.117 \\
0.195\end{array}$ & 1.691 & -0.220 \\
\hline $\mathrm{CH}_{2} \mathrm{~F}_{2}$ & $\begin{array}{l}-0.070 \\
-0.028\end{array}$ & $\begin{array}{r}0.557 \\
-0.966\end{array}$ & $\begin{array}{l}0.018 \\
0.009\end{array}$ & $\begin{array}{r}-0.006 \\
0.232\end{array}$ & 1.915 & -0.193 \\
\hline $\mathrm{CHF}_{3}$ & $\begin{array}{l}0 \\
-0.031\end{array}$ & $\begin{array}{r}0.708 \\
-0.825\end{array}$ & $\begin{array}{l}0 \\
0.004\end{array}$ & $\begin{array}{l}0.105 \\
0.261\end{array}$ & 1.646 & -0.104 \\
\hline $\mathrm{CF}_{4}$ & 0 & -0.667 & 0 & 0.285 & 0 & 0 \\
\hline $\mathrm{CF}_{3} \mathrm{Cl}$ & $\begin{array}{c}-0.012 \\
0\end{array}$ & $\begin{array}{l}-0.719 \\
-0.236\end{array}$ & $\begin{array}{c}-0.025 \\
0\end{array}$ & $\begin{array}{r}0.344 \\
-0.171\end{array}$ & 0.545 & -0.275 \\
\hline $\mathrm{CF}_{2} \mathrm{Cl}_{2}$ & $\begin{array}{l}-0.010 \\
-0.003\end{array}$ & $\begin{array}{l}-0.770 \\
-0.336\end{array}$ & $\begin{array}{l}-0.010 \\
-0.070\end{array}$ & $\begin{array}{l}-0.386 \\
-0.092\end{array}$ & 0.517 & -0.254 \\
\hline $\mathrm{CFCl}_{3}$ & $\begin{array}{c}0 \\
-0.004\end{array}$ & $\begin{array}{l}-0.811 \\
-0.431 \\
\end{array}$ & $\begin{array}{c}0 \\
-0.047 \\
\end{array}$ & $\begin{array}{r}0.402 \\
-0.021 \\
\end{array}$ & 0.435 & -0.172 \\
\hline
\end{tabular}

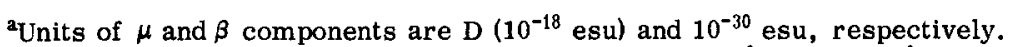

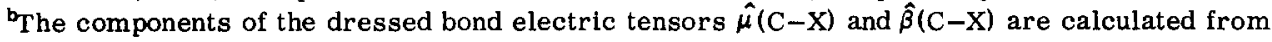
Eqs. (15) and (17), respectively, with axis conventions as defined in the text of the Appendix. $\hat{\beta}_{x \sigma \sigma}=\hat{\beta}_{x x x}+\hat{\beta}_{x y y}+\hat{\beta}_{x z z} ; \hat{\beta}_{z o \sigma}=\hat{\beta}_{z x}+\hat{\beta}_{z y y}+\hat{\beta}_{z z z}$.

${ }^{c}$ The molecular observables $\mu$ and $\beta$ are defined in Sec. II, with choice of molecular $Z$ axis such that $\mu$ is always positive. See also Figs. 3 and 4 for a comparison with preferred values and with BAA results.

${ }^{d}$ Compare with preferred value of $0.30(6) \mathrm{D}$ from Table III.

TABLE VII. Dressed bond and molecular $\hat{\alpha}$ parameters, from ISM calculations for halogenated methanes. ${ }^{2}$

\begin{tabular}{|c|c|c|c|c|c|c|c|c|}
\hline \multirow{2}{*}{$\begin{array}{l}\text { Molecule } \\
\mathrm{CX}_{n} \mathrm{Y}_{4-n}\end{array}$} & \multicolumn{5}{|c|}{$\begin{array}{l}\text { Dressed parameters for } \mathrm{C}-\mathrm{X} \text { (upper entry) and } \mathrm{C}-\mathrm{Y} \\
\text { (lower entry) bonds }{ }^{\mathrm{b}}\end{array}$} & \multicolumn{3}{|c|}{ Molecular observables ${ }^{c}$} \\
\hline & $\hat{\alpha}_{1}$ & $\hat{\alpha}_{2}$ & $\hat{\alpha}_{3}$ & $\hat{\alpha}_{4}$ & $\hat{\alpha}_{5}$ & $\alpha^{\omega}$ & $10^{3} \rho$ & $\left(\alpha_{Z Z Z}^{\omega}-\alpha^{\omega}\right)$ \\
\hline $\mathrm{CCl}_{4}$ & 2.644 & $0.581^{\mathrm{d}}$ & 0 & 0 & 0 & 10.58 & 0 & 0 \\
\hline $\mathrm{CHCl}_{3}$ & $\begin{array}{l}0.683 \\
2.606\end{array}$ & $\begin{array}{l}0.021 \\
0.538\end{array}$ & $\begin{array}{l}0 \\
0.093\end{array}$ & $\begin{array}{l}0 \\
-0.216\end{array}$ & $\begin{array}{l}0 \\
0.076\end{array}$ & 8.50 & 6.25 & -1.74 \\
\hline $\mathrm{CH}_{2} \mathrm{Cl}_{2}$ & $\begin{array}{l}0.650 \\
2.586\end{array}$ & $\begin{array}{l}0.029 \\
0.484\end{array}$ & $\begin{array}{r}0.085 \\
-0.062\end{array}$ & $\begin{array}{l}-0.081 \\
-0.254\end{array}$ & $\begin{array}{l}0.004 \\
0.094\end{array}$ & 6.47 & 10.38 & -0.41 \\
\hline $\mathrm{CH}_{3} \mathrm{Cl}$ & $\begin{array}{l}0.639 \\
2.586\end{array}$ & $\begin{array}{l}0.044 \\
0421\end{array}$ & $\begin{array}{l}-0.062 \\
0\end{array}$ & $\begin{array}{l}-0.094 \\
0\end{array}$ & $\begin{array}{l}0.004 \\
0\end{array}$ & 4.50 & 8.55 & 1.08 \\
\hline $\mathrm{CH}_{4}$ & 0.661 & $0.075^{\mathrm{d}}$ & 0 & 0 & 0 & 2.64 & 0 & 0 \\
\hline $\mathrm{CH}_{3} \mathrm{~F}$ & $\begin{array}{l}0.632 \\
0.608\end{array}$ & $\begin{array}{l}0.038 \\
0.134\end{array}$ & $\begin{array}{l}0.001 \\
0\end{array}$ & $\begin{array}{l}0.023 \\
0\end{array}$ & $\begin{array}{l}0.017 \\
0\end{array}$ & 2.50 & 0.50 & 0.14 \\
\hline $\mathrm{CH}_{2} \mathrm{~F}_{2}$ & $\begin{array}{l}0.628 \\
0.641\end{array}$ & $\begin{array}{l}0.035 \\
0.115\end{array}$ & $\begin{array}{r}0.000 \\
-0.002\end{array}$ & $\begin{array}{r}0.024 \\
-0.004\end{array}$ & $\begin{array}{l}0.013 \\
0.009\end{array}$ & 2.54 & 0.64 & -0.05 \\
\hline $\mathrm{CHF}_{3}$ & $\begin{array}{l}0.652 \\
0.682\end{array}$ & $\begin{array}{l}0.064 \\
0.130\end{array}$ & $\begin{array}{l}0 \\
0.001\end{array}$ & $\begin{array}{l}0 \\
0.006\end{array}$ & $\begin{array}{l}0 \\
0.006\end{array}$ & 2.70 & 0.27 & -0.11 \\
\hline
\end{tabular}




\begin{tabular}{|c|c|c|c|c|c|c|c|c|}
\hline \multirow{2}{*}{$\begin{array}{l}\text { Molecule } \\
\mathrm{CX}_{n} \mathrm{Y}_{4-n}\end{array}$} & \multicolumn{5}{|c|}{$\begin{array}{c}\text { Dressed parameters for } \mathrm{C}-\mathrm{X} \text { (upper entry) and } \mathrm{C}-\mathrm{Y} \\
\text { (lower entry) bonds }{ }^{\mathrm{b}}\end{array}$} & \multicolumn{3}{|c|}{ Molecular observables ${ }^{c}$} \\
\hline & $\hat{\alpha}_{1}$ & $\hat{\alpha}_{2}$ & $\hat{\alpha}_{3}$ & $\hat{\alpha}_{4}$ & $\hat{\alpha}_{5}$ & $\alpha^{\omega}$ & $10^{3} p$ & $\left(\alpha_{Z Z}^{\omega}-\alpha^{\omega}\right)$ \\
\hline $\mathrm{CF}_{4}$ & 0.728 & $0.179^{d}$ & 0 & 0 & 0 & 2.91 & 0 & 0 \\
\hline $\mathrm{CF}_{3} \mathrm{Cl}$ & $\begin{array}{l}0.723 \\
2.541\end{array}$ & $\begin{array}{l}0.171 \\
0.433\end{array}$ & $\begin{array}{l}-0.037 \\
0\end{array}$ & $\begin{array}{l}0.091 \\
0\end{array}$ & $\begin{array}{l}-0.016 \\
0\end{array}$ & 4.71 & 4.45 & 0.81 \\
\hline $\mathrm{CF}_{2} \mathrm{Cl}_{2}$ & $\begin{array}{l}0.718 \\
2.580\end{array}$ & $\begin{array}{l}0.162 \\
0.486\end{array}$ & $\begin{array}{r}0.038 \\
-0.091\end{array}$ & $\begin{array}{l}0.092 \\
0.281\end{array}$ & $\begin{array}{l}-0.016 \\
-0.054\end{array}$ & 6.60 & 6.40 & -0.27 \\
\hline $\mathrm{CFCl}_{3}$ & $\begin{array}{l}0.722 \\
2.605\end{array}$ & $\begin{array}{l}0.150 \\
0.538\end{array}$ & $\begin{array}{l}0 \\
0.089\end{array}$ & 0.200 & $\begin{array}{l}0 \\
-0.037\end{array}$ & 8.54 & 4.40 & -1.47 \\
\hline
\end{tabular}

aUnits of $\alpha$ components are $\AA^{3}\left(10^{-24} \mathrm{~cm}^{3}\right)$. The depolarization ratio $\rho$ is dimensionless.

The dressed bond polarizability tensor $\hat{\alpha}(\mathrm{C}-\mathrm{X})$ is calculated from Eq. (16), with axis conventions and components $\hat{\alpha}_{n}(n=1-5)$ as defined in the text of the Appendix.

${ }^{c}$ The molecular observables $\alpha, \rho$, and $\left(\alpha_{z z}-\alpha\right)$ are defined in Sec. II. See also Figs, 1, 5, and 6 for a comparison with preferred values and with BAA results.

${ }^{d}$ Compare with the following preferred values of $\hat{\alpha}_{2}(\mathrm{C}-\mathrm{X})=\Delta \hat{\alpha}(\mathrm{C}-\mathrm{X}) / 3$ from Table IIJ : $\mathrm{CCl}_{4}, 0.63(7) ; \mathrm{CH}_{4}, 0.09(1) ; \mathrm{CF}_{4}$, $0.19(2)$. Also, corresponding BAA estimates of $\hat{\alpha}_{2}(\mathrm{C}-\mathrm{X})$ from Table V are: $\mathrm{CCl}_{4}, 0.70(1) ; \mathrm{CH}_{4}, 0.10(1) ; \mathrm{CF}_{4}, 0.18(1)$.

TABLE VIII. Dressed bond and molecular $\hat{\gamma}$ parameters, from ISM calculations for halogenated methanes. ${ }^{2}$

\begin{tabular}{|c|c|c|c|c|c|c|}
\hline \multirow{2}{*}{$\begin{array}{l}\text { Molecule } \\
\mathrm{CX}_{n} \mathrm{Y}_{4-n}\end{array}$} & \multicolumn{4}{|c|}{$\begin{array}{c}\text { Dressed parameters for } \mathrm{C}-\mathrm{X} \text { (upper entry) and } \mathrm{C}-\mathrm{Y} \\
\text { (lower entry) bonds }{ }^{\mathrm{b}}\end{array}$} & \multirow[b]{2}{*}{$\hat{\gamma}_{5}$} & \multirow{2}{*}{$\begin{array}{c}\text { Molecular } \\
\text { observable }^{\mathrm{c}} \\
\gamma \\
\end{array}$} \\
\hline & $\hat{\gamma}_{1}$ & $\hat{\gamma}_{2}$ & $\hat{\gamma}_{3}$ & $\hat{\gamma}_{4}$ & & \\
\hline $\mathrm{CCl}_{4}$ & 0.562 & 0.284 & 0 & 0 & 0 & 1.350 \\
\hline $\mathrm{CHCl}_{3}$ & $\begin{array}{l}0.112 \\
0.525\end{array}$ & $\begin{array}{l}0.127 \\
0.260\end{array}$ & $\begin{array}{l}0 \\
0.044\end{array}$ & $\begin{array}{c}0 \\
-0.092\end{array}$ & $\begin{array}{l}0 \\
0.008\end{array}$ & 1.011 \\
\hline $\mathrm{CH}_{2} \mathrm{Cl}_{2}$ & $\begin{array}{l}0.117 \\
0.482\end{array}$ & $\begin{array}{l}0.133 \\
0.232\end{array}$ & $\begin{array}{r}0.008 \\
-0.041\end{array}$ & $\begin{array}{l}-0.009 \\
-0.104\end{array}$ & $\begin{array}{l}0.014 \\
0.011\end{array}$ & 0.719 \\
\hline $\mathrm{CH}_{3} \mathrm{Cl}$ & $\begin{array}{l}0.118 \\
0.425\end{array}$ & $\begin{array}{l}0.134 \\
0.194\end{array}$ & $\begin{array}{l}-0.005 \\
0\end{array}$ & $\begin{array}{l}-0.006 \\
0\end{array}$ & $\begin{array}{l}0.016 \\
0\end{array}$ & 0.467 \\
\hline $\mathrm{CH}_{4}$ & 0.110 & 0.125 & 0 & 0 & 0 & 0.264 \\
\hline $\mathrm{CH}_{3} \mathrm{~F}$ & $\begin{array}{l}0.117 \\
0.091\end{array}$ & $\begin{array}{l}0.129 \\
0.094\end{array}$ & $\begin{array}{l}0.002 \\
0\end{array}$ & $\begin{array}{l}0.005 \\
0\end{array}$ & $\begin{array}{l}-0.011 \\
0\end{array}$ & 0.265 \\
\hline $\mathrm{CH}_{2} \mathrm{~F}_{2}$ & $\begin{array}{l}0.096 \\
0.070\end{array}$ & $\begin{array}{l}0.107 \\
0.078\end{array}$ & $\begin{array}{r}-0.002 \\
0.000\end{array}$ & $\begin{array}{l}0.005 \\
0.001\end{array}$ & $\begin{array}{l}-0.010 \\
-0.008\end{array}$ & 0.200 \\
\hline $\mathrm{CHF}_{3}$ & $\begin{array}{l}0.060 \\
0.051\end{array}$ & $\begin{array}{l}0.076 \\
0.041\end{array}$ & $\begin{array}{l}0 \\
0.000\end{array}$ & $\begin{array}{c}0 \\
-0.004\end{array}$ & $\begin{array}{c}0 \\
-0.010\end{array}$ & 0.128 \\
\hline $\mathrm{CF}_{3}$ & 0.037 & -0.002 & 0 & 0 & 0 & 0.088 \\
\hline $\mathrm{CF}_{3} \mathrm{Cl}$ & $\begin{array}{l}0.054 \\
0.378\end{array}$ & $\begin{array}{l}0.040 \\
0.091\end{array}$ & $\begin{array}{l}-0.018 \\
0\end{array}$ & $\begin{array}{c}-0.065 \\
0\end{array}$ & $\begin{array}{c}-0.025 \\
0\end{array}$ & 0.325 \\
\hline $\mathrm{CF}_{2} \mathrm{Cl}_{2}$ & $\begin{array}{l}0.073 \\
0.467\end{array}$ & $\begin{array}{l}0.077 \\
0.168\end{array}$ & $\begin{array}{r}0.022 \\
-0.056\end{array}$ & $\begin{array}{r}-0.066 \\
0.144\end{array}$ & $\begin{array}{l}-0.028 \\
-0.037\end{array}$ & 0.648 \\
\hline $\mathrm{CFCl}_{3}$ & $\begin{array}{l}0.095 \\
0.515\end{array}$ & $\begin{array}{l}0.094 \\
0.231\end{array}$ & $\begin{array}{l}0 \\
0.040\end{array}$ & $\begin{array}{l}0 \\
0.092\end{array}$ & $\begin{array}{c}0 \\
-0.013\end{array}$ & 0.983 \\
\hline
\end{tabular}

${ }^{2}$ Units of $\gamma$ components are $10^{-36}$ esu.

The dressed bond hyperpolarizability tensor $\hat{\gamma}(\mathrm{C}-\mathrm{X})$ is calculated from Eq. (18), with axis conventions and components $\hat{\gamma}_{n}(n=1-5)$ as defined in the text of the Appendix.

The molecular observable $\gamma$ is defined in Sec. II. See also Fig. 2 for a comparison with preferred values and with $B A A$ results. 
molecular observables $\left(\mu, \alpha, \rho, \alpha_{z z}-\alpha, \beta, \gamma\right)$ and four bond observables $\left[\hat{\mu}(\mathrm{C}-\mathrm{H})\right.$ and $\Delta \hat{\alpha}(\mathrm{C}-\mathrm{X})$ in $\left.\mathrm{CX}_{4}\right]$ all included in the fit; all 24 bare bond parameters allowed to vary. The corresponding bare bond parameters determined by these calculations have been tabulated above in part $A$ of Table $V$. Values of the resulting dressed bond parameters and molecular observables are presented in Tables VI-VIII.

Some comments with regard to bond axis conventions and to the dressed bond tensor components for $\hat{\alpha}$ and $\hat{\gamma}$ are necessary at this point. The $z$ axis of each bond is taken to be the symmetry axis of the bare bond and to be directed out from the central $\mathrm{C}$ atom, as established in Sec. III. The corresponding $x$ axis of each bond (whether in a $\mathrm{CX}_{3} \mathrm{Y}$-, or $\mathrm{CX}_{2} \mathrm{Y}_{2}$-type molecule) is taken to lie in a plane of symmetry and to have a negative projection on the $Z$ axis of the molecule; the choice of this molecular $Z$ axis has been discussed in Sec. II. The specification of the $x$ axis of a bond in $\mathrm{CX}_{4}$ does not affect any of the properties considered in this Appendix. The tensor properties $\hat{\alpha}$ and $\hat{\gamma}$ of a dressed bond have been expanded in terms of orthogonal irreducible spherical tensor components $\hat{\alpha}_{n}$ and $\hat{\gamma}_{n}$, respectively, where $n=1-5$. In the case of $\hat{\alpha}$, these are related to Cartesian components $\hat{\alpha}_{r s}$ by:

$$
\begin{aligned}
& \hat{\alpha}_{1}=\left(\hat{\alpha}_{x x}+\hat{\alpha}_{y y}+\hat{\alpha}_{z z}\right) / 3, \\
& \hat{\alpha}_{2}=\left(2 \hat{\alpha}_{z z}-\hat{\alpha}_{x x}-\hat{\alpha}_{y y}\right) / 6, \\
& \hat{\alpha}_{3}=\left(-\hat{\alpha}_{x x}+\hat{\alpha}_{y y}\right) / 2, \\
& \hat{\alpha}_{4}=\left(\hat{\alpha}_{x z}+\hat{\alpha}_{z x}\right) / 2, \\
& \hat{\alpha}_{5}=\left(\hat{\alpha}_{x z}-\hat{\alpha}_{z x}\right) / 2 .
\end{aligned}
$$

The parameters $\hat{\gamma}_{n}$ are similarly related to Cartesian components $\hat{\gamma}_{\text {rsoa }}$, where the repeated suffixes imply a summation over $\sigma=x, y$, and $z$.

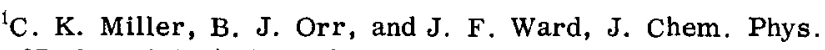
67,2109 (1977), hereafter referred to as $I$.

${ }^{2}$ C. K. Miller and J. F. Ward, Phys. Rev. A 16, 1179 (1977).

${ }^{3}$ For a review, see M. P. Bogaard and B. J. Orr, Interna-

tional Review of Science. Physical Chemistry, edited by A.

D. Buckingham (Butterworths, London, 1975), Ser. 2, Vol. 2, pp. 149-194.

"The formula for $\kappa^{2}$ which appears in the "Comments" column of Table VI of Ref. 1 should contain the numerical factor 18 in the denominator, in place of the factor 9 which erroneously appears.

${ }^{5} \mathrm{G}$. W. Hills and W. J. Jones, J. Chem. Soc. Faraday Trans. II 71,812 (1975).

${ }^{6}$ W. F. Murphy, J. Chem. Phys. 67, 5877 (1977).

${ }^{7}$ M. P. Bogaard, B. J. Orr, W. F. Murphy, K. Srinivasan, and A. D. Buckingham (to be published).

${ }^{8}$ N. J. Bridge and A. D. Buckingham, Proc. R. Soc. London, Ser. A 295, 334 (1966).

${ }^{8}$ A. K. Burnham, L. W. Buxton, and W. H. Flygare, J. Chem. Phys. 67, 4990 (1977).

${ }^{10}$ M. P. Bogaard, B. J. Orr, A. D. Buckingham, and G. L. D. Ritchie, J. Chem. Soc. Faraday Trans. II 74, 1573 (1978).

${ }^{11} \mathrm{~A}$. D. Buckingham and B. J. Orr, Trans. Faraday Soc. 65, 673 (1969).
${ }^{12}$ M. P. Bogaard, A. D. Buckingham, R. K. Pierens, and A. H. White, J. Chem. Soc. Faraday Trans. I 74, 3008 (1978).

${ }^{13}$ F. Baas and K. D. van den Hout, Physica (Utrecht) A 95, 597 (1979).

${ }^{14}$ B. J. Orr, in Nonlinear Behavior of Molecules, Atoms and Ions in Electric, Magnetic and Electromagnetic Fields (Proceedings of conference at Fontevraud, France in September, 1978), edited by L. Néel (Elsevier, Amsterdam, 1979), pp. 227-236.

${ }^{15}$ J. F. Ward and I. J. Bigio, Phys. Rev. A 11, 60 (1975).

${ }^{16}$ Sources and values of $10^{34} \Omega /$ esu for $\mathrm{CH}_{4}$ are indicated in square brackets after each of the following references: $P$. Isnard, D. Robert, and L. Galatry, Mol. Phys. 31, 1789 (1976) (theoretical modeling of bulk gas properties, \pm 2.30 ); R. D. Amos, Molec. Phys. 38, 33 (1979) (ab initio theory, $+1.85)$; I. G. John, G. B. Bacskay, and N. Hush, Chem. Phys. 51, 49 (1980) (ab initio theory, +1.6).

${ }^{17}$ R. H. Pritchard and C. W. Kern, J. Am. Chem. Soc. 91, 1631 (1969); M. S. Gordon and W. England, J. Am. Chem Soc. 94, 5168 (1972); G. Riley, S. Suzuki; and W. J. Orville-Thomas, J. Chem. Soc. Faraday Trans. II 74, 1947 (1978): A. Hinchliffe and I. F. Kidd, J. Chem. Soc. Faraday Trans. II 76, $172(1980)$.

${ }^{18}$ D. van der Hart and W. H. Flygare, Mol. Phys. 18, 77 (1970); W. H. Flygare and R. C. Benson, Mol. Phys. 20, 225 (1971).

${ }^{19}$ We use the shorthand notation $\langle T \cdot \chi\rangle_{i}$ to represent summations of the form $\sum_{j \neq i} T_{i j} \chi_{j}$, where $j$ is a dummy suffix. The notation $\langle\mathbf{T} \cdot \chi\rangle_{i}^{s}$ denotes a product of $s$ such terms, each involving summation over a distinct dummy suffix. See I for further details.

${ }^{20}$ See, for example, A. D. Buckingham, Discuss. Faraday Soc. 40, 232 (1965); Advances in Chemical Physics, edited by J. O. Hirschfelder (Interscience, New York, 1967), Vol. 12 , p. 107.

${ }^{21}$ C. P. Smyth and K. B. McAlpine, J. Chem. Phys. 1, 190 (1933).

${ }^{22}$ J. Applequist, J. R. Carl, and K. -K. Fung, J. Am. Chem. Soc. 94,2952 (1972).

${ }^{23}$ It is not unusual that the $\chi^{2}$ parameter in this context can be much larger than 1 , since the discrepancies between observed and fitted values are dominated by shortcomings of the model rather than by experimental uncertainties.

${ }^{24} \mathrm{P}$. D. Maker, in Physics of Quantum Electronics, edited by P. L. Kelley, B. Lax, and P. Tannenwald (McGraw-Hill, New York, 1966), p. 60; P. D. Maker, Phys. Rev. A 1, 923 (1970).

${ }^{25}$ S. P. Liebmann and J. W. Moskowitz, J. Chem. Phys. 54, 3622 (1971).

${ }^{26}$ R. D. Amos, Mol. Phys. 38, 33 (1979).

${ }^{27}$ P. Lazzeretti and R. Zanasi, J. Chem. Phys. (to be published).

${ }^{28} \mathrm{H}$. Werner and W. Meyer, Mol. Phys. 31, 855 (1976).

${ }^{29}$ P. A. Christiansen and E. A. McCullough, Chem. Phys. Lett. 63, 570 (1979); R. J. Bartlett and G. D. Purvis, Phys. Rev. A 20, 1313 (1979).

${ }^{30} \mathrm{~J}$. Applequist, Acc. Chem. Res, 10, 79 (1977).

${ }^{31}$ K. R. Sundberg, J. Chem. Phys. 66, 114 (1977); 66, 1475 (1977).

${ }^{32} \mathrm{~J}$. Applequist and C. O. Quicksall, J. Chem. Phys. 66, 3455 (1977).

${ }^{33}$ J. Applequist, J. Chem. Phys. 58, 4251 (1973); J. Am. Chem. Soc. 95, 8255 (1973); 95, 8258 (1973); K. R. Sundberg, J. Chem. Phys. 68, 5271 (1978); P. L. Prasad, ibid. 70,5582 (1979).

${ }^{34}$ M. L. Olson and K. R. Sundberg, J. Chem. Phys. 69, 5400 (1978); J. Applequist, ibid. 71, 1983 (1979); 71, 4324 (1979); 71, 4332 (1979).

${ }^{35}$ L. Silberstein, Philos. Mag. 33, 92 (1917). 